\title{
REDES PARA LA COOPERACIÓN A DISTINTAS ESCALAS: ASOCIACIONISMO MUNICIPAL, REGIONES EUROPEAS $Y$ PROGRAMAS TRANSNACIONALES ${ }^{1}$. \\ NETWORKS FOR COOPERATION AT DIFFERENT SCALES: MUNICIPAL ASSOCIATIONS, EUROPEAN REGIONS AND TRANSNATIONAL PROGRAMS.
}

\author{
Jesús Ventura Fernández \\ Universidad de Sevilla \\ jventura@us.es
}

Recibido: marzo, 2012.

Versión final aceptada: abril, 2013.

PALABRAS CLAVE: organización territorial, ordenación del territorio, asociacionismo municipal, regiones europeas, programas transnacionales, cooperación internacional.

KEYWORDS: subdivisions, land planning, municipal associations, european regions, transnational programs, international cooperation.

RESUMEN

La premisa fundamental de la que parte este estudio se fundamenta en el hecho de asumir los vínculos existentes entre organización territorial y ordenación del territorio, en el sentido de aceptar que el concepto convergente de desarrollo tiene en la actualidad un carácter integral, compendio de crecimiento económico, equidad socioterritorial y sustentabilidad ecológica, aplicado a distintas escalas espaciales. De esta manera se pueden implementar diferentes asociaciones intermunicipales, distintos proyectos de construcción de macrorregiones, e incluso propuestas transnacionales de cooperación interterritorial.

\section{ABSTRACT}

The basic premise of this work is to accept the links between territorial organization and Land planning, because the concept of development is nowdays integral, including economic growth, social and territorial cohesion and environmental sustainability, at different spatial scales. In this case, we study different municipal associations, several construction projects of europeanmacro-regions and even some transnational proposals about territorial cooperation.

\footnotetext{
${ }^{1}$ El presente artículo procede de la ponencia presentada en las Jornadas de Estudios Regionales: Redes y sus territorios: Incidencia en el desarrollo regional. AGE. Sevilla, Junio de 2012.
}

ISSN: 0212-8594 ISSN-e: 2340-2776. № DOI: http://dx.doi.org/10.12795/rea.2013.i30.03 


\section{CONCEPTO GEOGRÁFICO DE RED: HITOS ESENCIALES.}

Si partimos de la definición de red como la de un conjunto de elementos organizados para un determinado fin, que es la que nos facilita el Diccionario de la Real Academia Española de la Lengua, enseguida comprendemos que se trata de un concepto con claros contenidos geográficos, ya que estos elementos se acoplan a un espacio, bien físico o bien virtual. De hecho en esa misma acepción del DRAE se habla de redes para el abastecimiento de aguas, telegráficas o telefónicas, ferroviarias o de carreteras,... Se trata, por consiguiente, de una idea directamente vinculada a las infraestructuras y por extensión a la ordenación territorial en sentido amplio, bien como disposición espontánea de los elementos geográficos o pretendidamente inducida a través de políticas públicas al respecto (Cano, G., 1990; Zoido, F., 1995-1996).

Ahora bien, estas ideas alcanzan su máxima expresión dentro del campo geográfico coincidiendo con la Nueva Geografía cuantitativa, de corte neopositivista, que comienza a desarrollarse en el mundo anglosajón desde los primeros años sesenta del pasado siglo XX. En este sentido de todos es conocida la importancia que al respecto de estas cuestiones tienen distintas aportaciones, entre las que cabe destacar la de Peter Haggett, Locational Analysis in Human Geography, de 1965, o la de este autor junto con Richard Chorley en 1969, Network analysis in Geography.

En palabras de Horacio Capel (2003), "el libro de Peter Haggett contribuyó a difundir un enfoque geometrizante, que defendían paralelamente otros autores como William Bunge en su Theoretical Geography (1962) y David Harvey en Explanation in Geography (1969). La búsqueda del orden locacional se convirtió en uno de los aspectos centrales de la indagación geográfica. Varias fases en el análisis realizado por Haggett se refieren a los nodos, las jerarquías y las áreas de influencia. Todo ello condujo al estudio de las redes, consideradas también por Peter Haggett y Richard J. Chorley desde una perspectiva positivista que permite analizar simultáneamente las redes físicas y humanas". Así pues, nos encontramos ya con una estructura topológica del territorio, fundamentada en nodos, redes y áreas, visión que con posterioridad será transferida de manera muy exitosa a las potentes herramientas informáticas que constituyen en la actualidad los GIS (Sistemas de Información Geográfica en castellano).

Además, Horacio Capel y Luis Urteaga (1986), desde una visión comprometidamente sociológica de la Geografía, entienden que dentro de los núcleos conceptuales específicos y esenciales de esta disciplina (sólo 5 sobre un total de 18) en dos de ellos aparece la idea de red de manera nítida:

“11) El poblamiento y las actividades humanas se encuentran organizados jerárquicamente: conocer las implicaciones de la jerarquía de ciudades y de áreas de influencia en una red urbana.

ISSN: 0212-8594 ISSN-e: 2340-2776. № DOI: http://dx.doi.org/10.12795/rea.2013.i30.03

REA 30 (2013):48-77

http://www.publius.us.es/estudios_andaluces 
12) Los movimientos y las mallas de transporte contribuyen a estructurar el espacio terrestre: conocer que el análisis topológico de las redes de transporte permite determinar su accesibilidad, centralidad y densidad".

Por todo ello no debe sorprendernos que múltiples autores, entre los que podríamos citar por ejemplo a Francisco Javier Antón Burgos y Juan Córdoba y Ordoñez (2003), incidan y profundicen en la línea de vincular redes y sistemas de transporte con métodos cada vez más sofisticados.

\section{LA COOPERACIÓN A DISTINTAS ESCALAS ESPACIALES.}

Entendemos la cooperación como la acción de actuar de manera conjunta con otros en la búsqueda de un mismo fin, lo que la aleja, por tanto, de la mera caridad cristiana y de la limosna o azaque como tercer pilar fundamental del Islam.

De hecho, existe en la actualidad la Organización para la Cooperación y el Desarrollo Económicos (OECD en francés), que es una organización de cooperación internacional, compuesta por 34 estados, cuyo objetivo es coordinar sus políticas económicas y sociales. Se fundó en 1960, y tiene su sede central en París, siendo sus idiomas oficiales el francés y el inglés. En la OCDE, los representantes de los estados miembros se reúnen para intercambiar información y armonizar políticas con el objetivo de maximizar su crecimiento económico y colaborar a su desarrollo y al de los países no miembros. La OCDE, conocida también como el "club de los países ricos», agrupa a países que proporcionaban al mundo el $70 \%$ del mercado mundial y representaban el $80 \%$ del PNB antes de la actual crisis económica. En realidad es la sucesora de la OECE (Organización Europea para la Cooperación Económica), resultado del Plan Marshall y de la Conferencia de los Dieciséis (Conferencia de Cooperación Económica Europea), que existió entre 1948 y 1960; de manera que la actual organización nació cuando veinte países, tanto de América del Norte como de Europa, se adhirieron a la «Convención de la OCDE» (París, 14 de diciembre de 1960).

En estos momentos, la OCDE se ha constituido en uno de los foros mundiales más influyentes, en el que se analizan y establecen orientaciones sobre temas de relevancia internacional como economía, educación y medioambiente. Los países miembros están comprometidos a aplicar sus principios de liberalización en los movimientos de capitales y servicios, así como el de no discriminación. Sin embargo, y desde una perspectiva crítica al sistema de producción capitalista, se le suele vincular con los organismos derivados de los acuerdos de la convención de las Naciones Unidas en Bretton Woods, New Hampshire, Estados Unidos (1944), y que están en el origen del Fondo Monetario Internacional (IFM) y del Banco Mundial (WB), como máximos valedores ideológicos, institucionales y financieros de este sistema económico.

Cabe mencionar también aquí al Programa de las Naciones Unidas para el Desarrollo (UNDP en inglés), creado en 1995, perteneciente al sistema de Naciones Unidas, y cuya

ISSN: 0212-8594 ISSN-e: 2340-2776. № DOI: http://dx.doi.org/10.12795/rea.2013.i30.03 REA 30 (2013):48-77

http://www.publius.us.es/estudios_andaluces 
función es contribuir a la mejora de la calidad de vida de los estados. Desde 1990 el PNUD publica su conocido Informe sobre Desarrollo Humano. Promueve el cambio y conecta los conocimientos, la experiencia y los recursos necesarios para ayudar a los pueblos a forjar una vida mejor. Se encuentra en 177 países, y su meta es ayudar a éstos a elaborar y a compartir soluciones que permitan responder a los retos del mundo actual: gobernabilidad democrática, reducción de la pobreza, prevención y recuperación en las catástrofes naturales, energía y medio ambiente, tecnología de la

Figura 1. Estados miembros de la OCDE (2012).

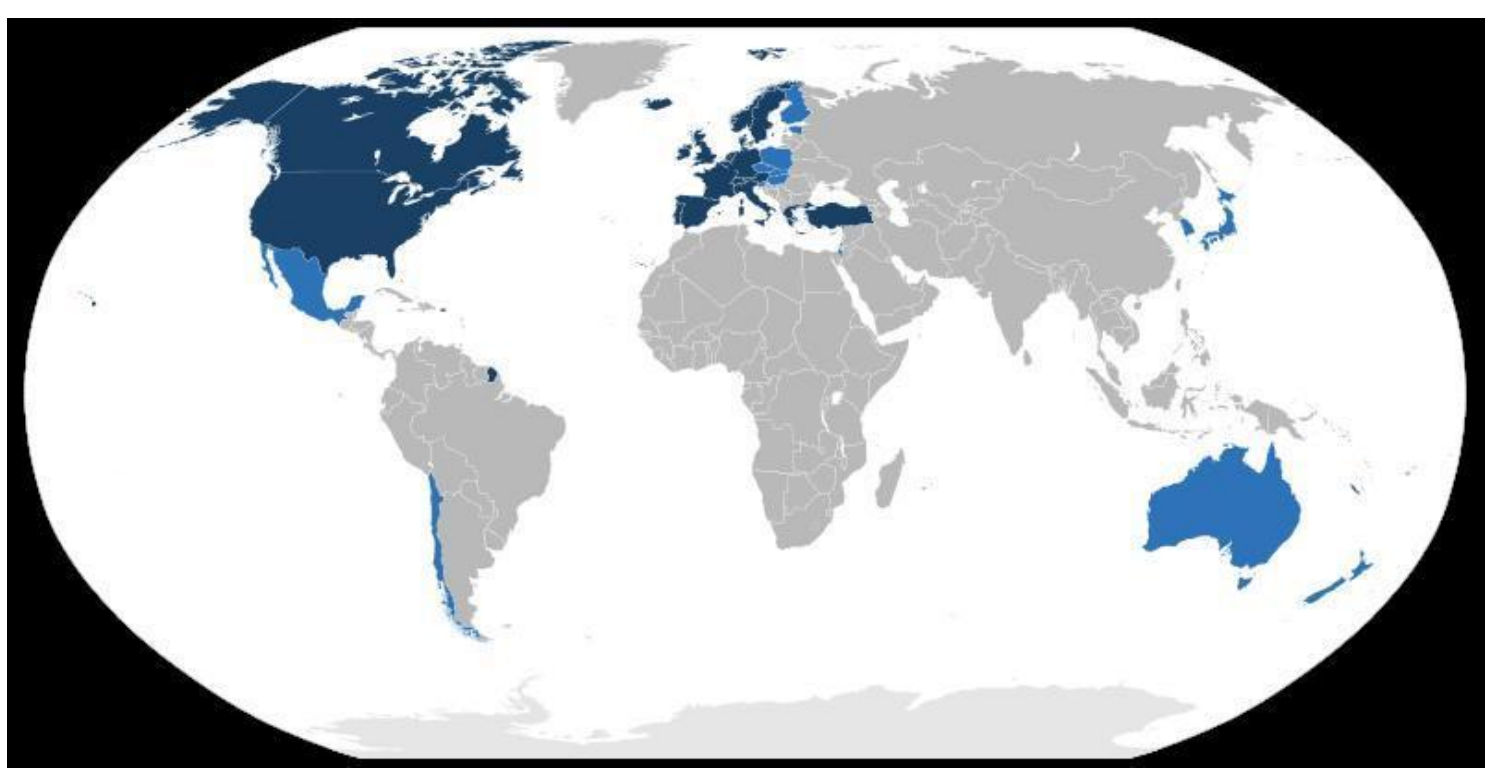

Fuente: Wikipedia (9/10/2012). En oscuro, estados fundadores; y en más claro, otros estados miembros.

información y las comunicaciones, y lucha contra el VIH-SIDA. Igualmente, se han establecido objetivos que reduzcan la enfermedad, el analfabetismo, y la discriminación contra la mujer. El PNUD es, en definitiva, una red internacional de las Naciones Unidas para el desarrollo socio-económico que actúa incluso en zonas del Mediterráneo Occidental, como la península de Tánger, región oriental en la frontera con Argelia, y provincias de los entornos de Marrakech y Fez, en el Reino de Marruecos.

A escala estatal española contamos con la Agencia Española de Cooperación Internacional para el Desarrollo (AECID), creada simplemente como $\mathrm{AECl}$ en noviembre de 1988, y dependiente, desde sus inicios y al igual que sucede en otros estados, del actual Ministerio de Asuntos Exteriores y Cooperación.

Quizás sea, no obstante, en la Ley 23/1998, de 7 de julio, de Cooperación Internacional para el Desarrollo, donde, en su Preámbulo, encontremos con mayor claridad los objetivos de esta institución. En él se viene a decir que a partir de que España dejara de ser considerada en 1981 como país receptor de ayuda internacional, la progresiva

ISSN: 0212-8594 ISSN-e: 2340-2776. № DOI: http://dx.doi.org/10.12795/rea.2013.i30.03 REA 30 (2013):48-77

http://www.publius.us.es/estudios_andaluces 
formulación y puesta en práctica de esta política de cooperación hubo de tener en cuenta hechos relevantes, como son, entre otros, el ingreso de nuestro país en los distintos Bancos Regionales de Desarrollo (Banco Interamericano, Banco Africano y Banco Asiático), complementados por la participación en todos aquellos organismos de carácter económico y financiero dedicados a la cooperación para el desarrollo, en particular los Fondos y Programas de la Unión Europea. Además, el ingreso de España en el Comité de Ayuda al Desarrollo de la OCDE, en diciembre de 1991, constituye un hito en la consolidación de nuestra cooperación para el desarrollo, en cuanto nos obliga a adaptarla y a coordinarla con la de los principales donantes del mundo, miembros del Comité, del organismo antes referido.

Por su parte, muchas comunidades autónomas españolas, en la época de bonanza económica, constituyeron sus propias agencias regionales al respecto de esta cuestión, como la Agencia Andaluza de Cooperación Internacional al Desarrollo (AACID), creada por Ley en 2006, aunque no entra en funcionamiento hasta junio de 2008, una vez aprobados sus Estatutos por el Decreto 1/2008, dependiendo de la Consejería de la Presidencia de la Junta de Andalucía.

La AACID tiene como objetivo fundamental optimizar, en términos de eficacia y economía, la gestión de los recursos públicos que la Administración Autonómica andaluza destina a la cooperación internacional para el desarrollo, si bien sus actuaciones nunca han sido relevantes, e incluso podemos decir que han ido languideciendo con el paso del tiempo, y más en el contexto de crisis actual, donde sólo se perduran acciones de carácter sectorial, con cierta tradición, en el Norte de Marruecos, bajo los impulsos directos de los departamentos de Obras Públicas y de Medio Ambiente de la Junta de Andalucía.

\section{ORGANIZACIÓN TERRITORIAL EN EL ESTADO AUTONÓMICO ESPAÑOL.}

La organización territorial del estado en España, entendida como la serie de demarcaciones que a distintas escalas se establecen para la mejor gestión administrativa de su territorio (Ventura y Fernández, 2011), se fundamenta, obviamente, en la Constitución Española de 1978. Dejando al margen su controvertido artículo segundo sobre nacionalidades y regiones españolas y el principio de solidaridad interterritorial en él recogido (tan cuestionado en estos momentos), resuelta evidente que es en el Título VII en el que se desarrolla con profusión toda esta cuestión, y, en concreto, la posible construcción del Estado Autonómico.

Recordemos que, en efecto, ésta es, en principio, una mera opción, según refleja el artículo 137 ("El Estado se organiza territorialmente en municipios, en provincias y en las Comunidades Autónomas que se constituyan. Todas estas entidades gozan de autonomía para la gestión de sus respectivos intereses"), reservada quizás para las mal denominadas nacionalidades históricas, a las que se hace referencia en la Disposición Transitoria Segunda ("Los territorios que en el pasado hubiesen plebiscitado

ISSN: 0212-8594 ISSN-e: 2340-2776. № DOI: http://dx.doi.org/10.12795/rea.2013.i30.03 
afirmativamente proyectos de Estatuto de autonomía y cuenten, al tiempo de promulgarse esta Constitución, con regímenes provisionales de autonomía, podrán proceder inmediatamente en la forma que se prevé en el apartado 2 del artículo 148, cuando así lo acordaren, por mayoría absoluta, sus órganos preautonómicos colegiados superiores, comunicándolo al Gobierno. El proyecto de Estatuto será elaborado de acuerdo con lo establecido en el artículo 151, numero 2, a convocatoria del órgano colegiado preautonómico); esto es, Cataluña, País Vasco y Galicia (comunidades todas ellas que cuentan a su vez con lengua propia...).

Finalmente, el Estado de las Autonomías se conformó, no obstante, en los primeros años de la década de los 80 del pasado siglo XX afectando a todo el territorio español, mediante comunidades autónomas que dispusieron, al menos en un primer momento, de un desigual grado de autogobierno, y que se basaron en la contigüidad física entre provincias (ratificadas por el anteriormente referido art. 137) o bien adoptaron un carácter uniprovincial, más los casos posteriores de las ciudades autónomas de Ceuta y Melilla en la costa norteafricana del Estrecho de Gibraltar y Mar de Alborán respectivamente.

Ahora bien, a pesar de lo exitoso de este esquema territorial sumamente descentralizado, podemos decir que casa mal con el mantenimiento de la red provincial de origen decimonónico (1833), homogeneizador y centralizador (Cano, 1990). No obstante, el mantenimiento en el tiempo de estas entidades, a pesar de algunas alteraciones de límites poco trascendentes (según podemos apreciar la figura 2), y el desdoblamiento de Canarias en las actuales provincias de Santa Cruz de Tenerife y Las Palmas (1927), ha contribuido al proceso de urbanización en España, y su desaparición podría traer consecuencias negativas para ámbitos muy despoblados, como son los que encontramos en la actualidad en el conjunto de la Meseta castellana... La tupida red municipios españoles (más de 8.000 y verdadera célula viva de nuestra organización territorial al estar vinculada al poblamiento), y las 17 comunidades autónomas, con distintos colores, quedan plasmadas también en la figura n‥ 3.

Además, se indica en la Carta Magna que "se podrán crear agrupaciones de municipios diferentes de la provincia" (art. 141.3), donde parece que se hace referencia implícita a áreas metropolitanas, mancomunidades de municipios, consorcios y otras figuras de cooperación territorial; más la especificidad de los casos insulares para los que se recoge en el artículo 141.4 que "las islas tendrán además su administración propia en forma de Cabildos o Consejos", en Canarias los primeros y en el archipiélago balear los segundos.

Por su parte, en el Capítulo III de este Título constitucional VIII sobre la organización territorial del Estado, dedicado ya a las comunidades autónomas, se viene a decir que "mediante la agrupación de municipios limítrofes, los Estatutos podrán establecer circunscripciones territoriales propias que gozarán de plena personalidad jurídica", lo

ISSN: 0212-8594 ISSN-e: 2340-2776. № DOI: http://dx.doi.org/10.12795/rea.2013.i30.03 REA 30 (2013):48-77

http://www.publius.us.es/estudios_andaluces 
que los especialistas en Derecho Administrativo y Constitucional suelen entender como una referencia directa a la posible creación de comarcas o de otras demarcaciones internas dentro de cada comunidad autónoma para la mejor gestión de sus distintas realidades territoriales.

En todo caso, recordemos que el recorrido territorial que va desde el ámbito submunicipal al provincial conforma la esfera de la Administración Local en España, existiendo al respecto un Registro de tales entidades, dependiente en la actualidad del Ministerio de Hacienda y Administraciones Públicas ( http://ssweb.mpt.es/REL/ ), y en el que se relejan todas las EATIMES (entidades de ámbito territorial inferior al municipal, herederas de las antiguas entidades menores y denominadas en Andalucía como Entidades Locales Autónomas -ELAs-), municipios, islas, mancomunidades, comarcas, áreas metropolitanas, provincias y otras agrupaciones (normalmente históricas, vinculadas por lo general al aprovechamiento forestal comunal), que, con sus correspondientes instituciones de gobierno, existen en estos momentos.

Para Andalucía, en su primer Estatuto de Autonomía (1981), se establecía en su artículo 5 que "por Ley del Parlamento Andaluz podrá regularse la creación de

Figura 2. Cambios en los límites interprovinciales desde su creación en 1833.

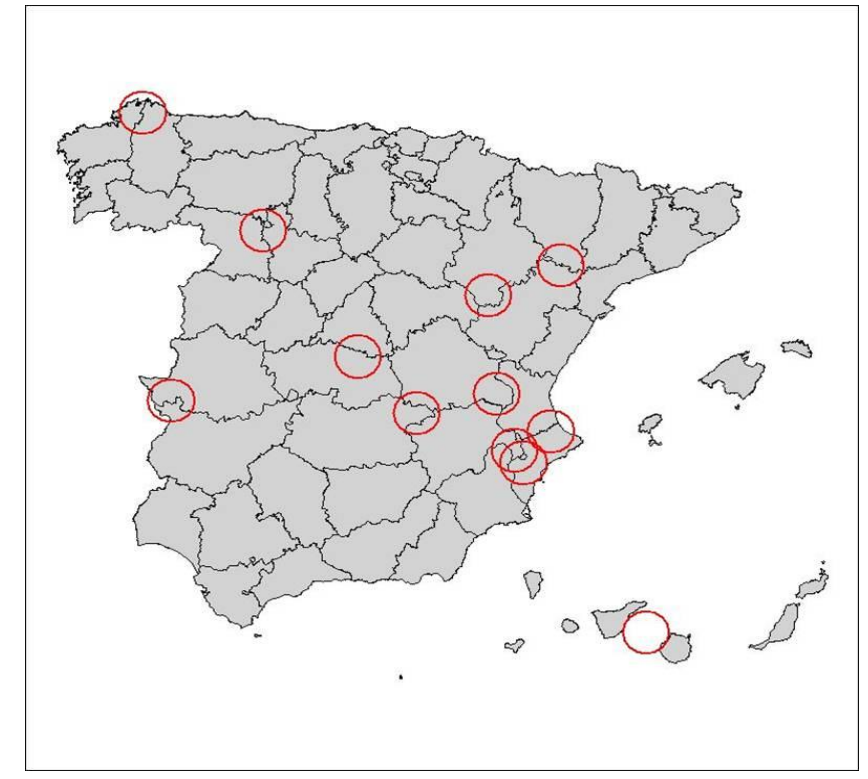

Fuente: Gráfico facilitado por Daniel Montero Cobos ( http://estudiodmc.wordpress.com/ ).

ISSN: 0212-8594 ISSN-e: 2340-2776. № DOI: http://dx.doi.org/10.12795/rea.2013.i30.03 REA 30 (2013):48-77 
Figura 3. Red de municipios españoles por Comunidades Autónomas.

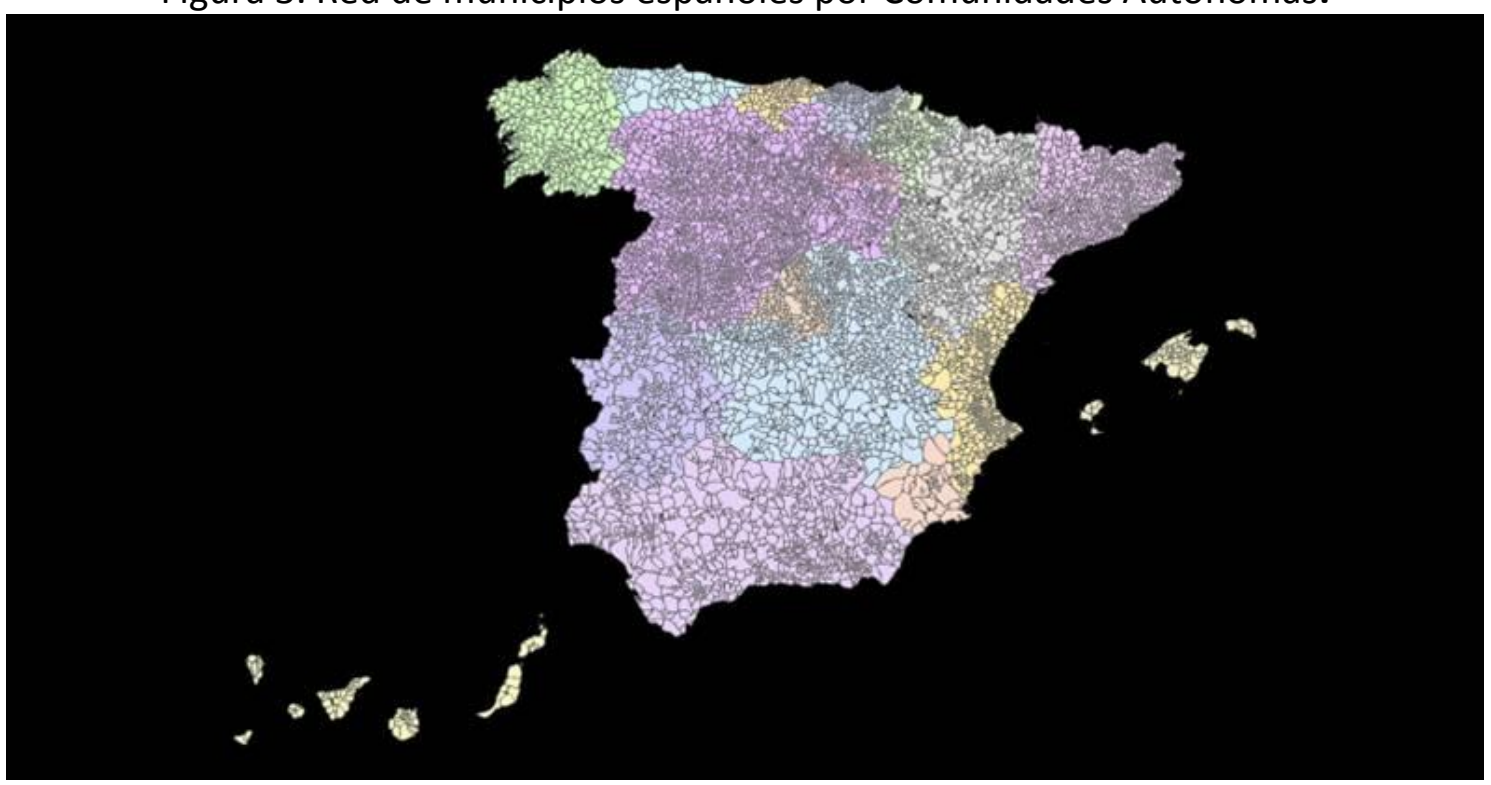

Fuente: Imágenes de los “municipios españoles” en el buscador Google (Internet).

comarcas integradas por municipios limítrofes dentro de la misma provincia, atendiendo a sus características geográficas, económicas, sociales e históricas. Se requerirá en todo caso el acuerdo de los Ayuntamientos afectados y la aprobación del Consejo de Gobierno". Ahora bien, el condicionante innecesario de la pertenencia de todos los municipios implicados a una única provincia, un teórico planteamiento holístico más que funcional de la comarcalización, y, sobre todo, la voluntariedad de pertenencia a la comarca correspondiente, hizo que la Propuesta planteada (1983) se diluyera en un mero Sistema de Ciudades (1986) apenas tenido en cuenta por las posteriores Bases para la Ordenación del Territorio de Andalucía (1990). Este modelo territorial, más teórico que real, queda en todo caso reflejado en la posterior figura no. 4.

No obstante, los estudios comarcales para todo el territorio andaluz vuelven a estar de actualidad una década después, con el Informe de Desarrollo Territorial de Andalucía, coordinado por el profesor Florencio Zoido (2001), en el que se parte de la idea de referir a ámbitos intermedios los objetivos de mantener la diversidad y erradicar la desigualdad o los desequilibrios territoriales existentes. La base comarcal utilizada se compone de 63 unidades (figura no. 5), fundamentada en el Estudio territorial para la delimitación de ámbitos comarcales de Andalucía, coordinado por Manuel Benabent (Arenal Consultores, 1998), y que fue realizada a partir de varios criterios, principalmente los funcionales y de voluntad política, considerando prácticas vigentes de cooperación intermunicipal. Sobre dicho mapa comarcal se efectuaron análisis de variables individualizadas o integradas por distintos métodos de relación (ponderaciones, análisis de componentes múltiples, y análisis clúster), y como

ISSN: 0212-8594 ISSN-e: 2340-2776. № DOI: http://dx.doi.org/10.12795/rea.2013.i30.03 
Figura 4. Proyecto de Comarcalización para Andalucía (1983).

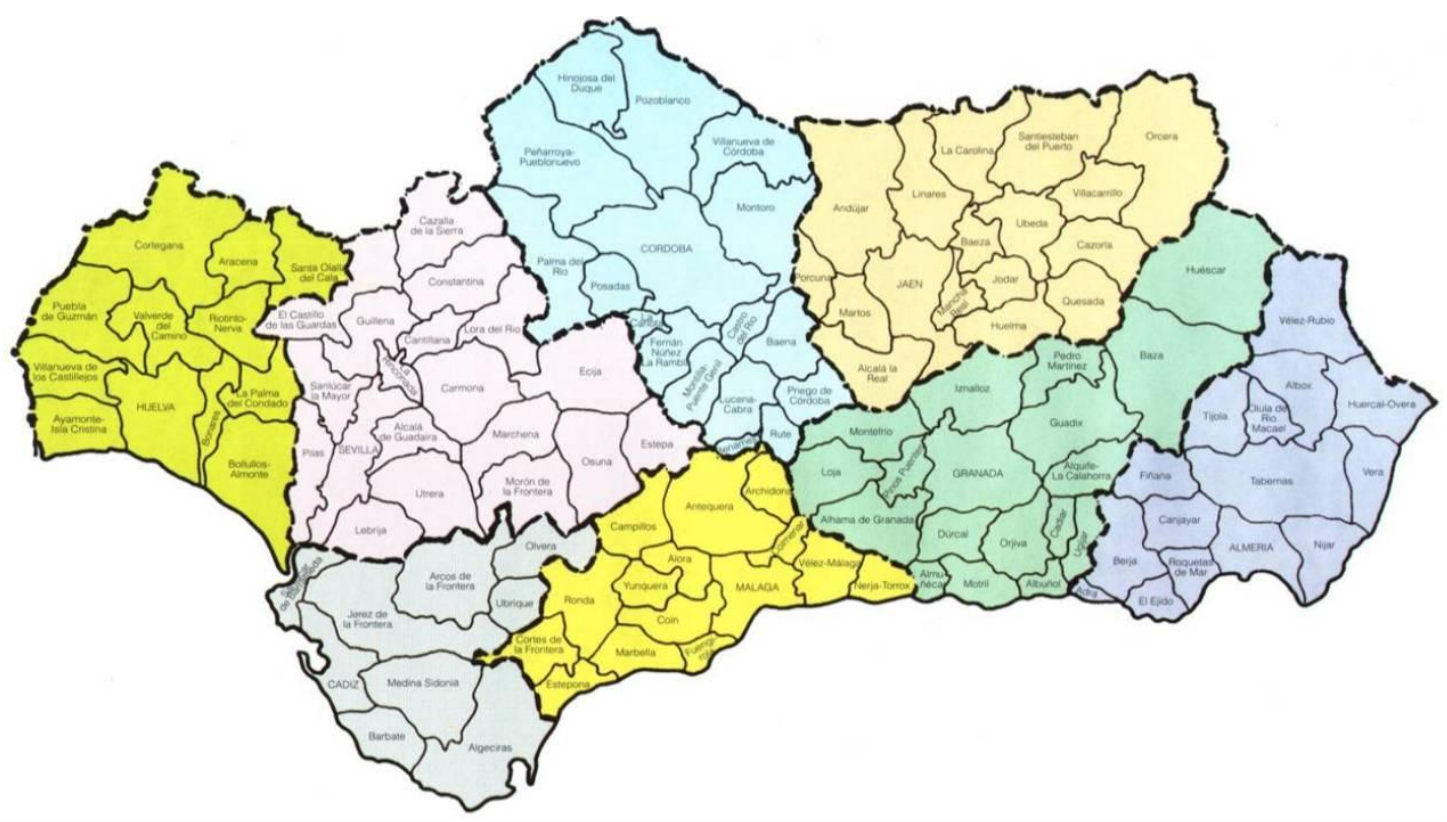

Fuente: CONSEJERÍA DE EDUCACIÓN Y CIENCIA (1991), Mapa Escolar de Andalucía 90-91, Junta de Andalucía.

Figura 5. Base comarcal del Informe de Desarrollo Territorial de Andalucía.

15.1. BASE COMARCAL.
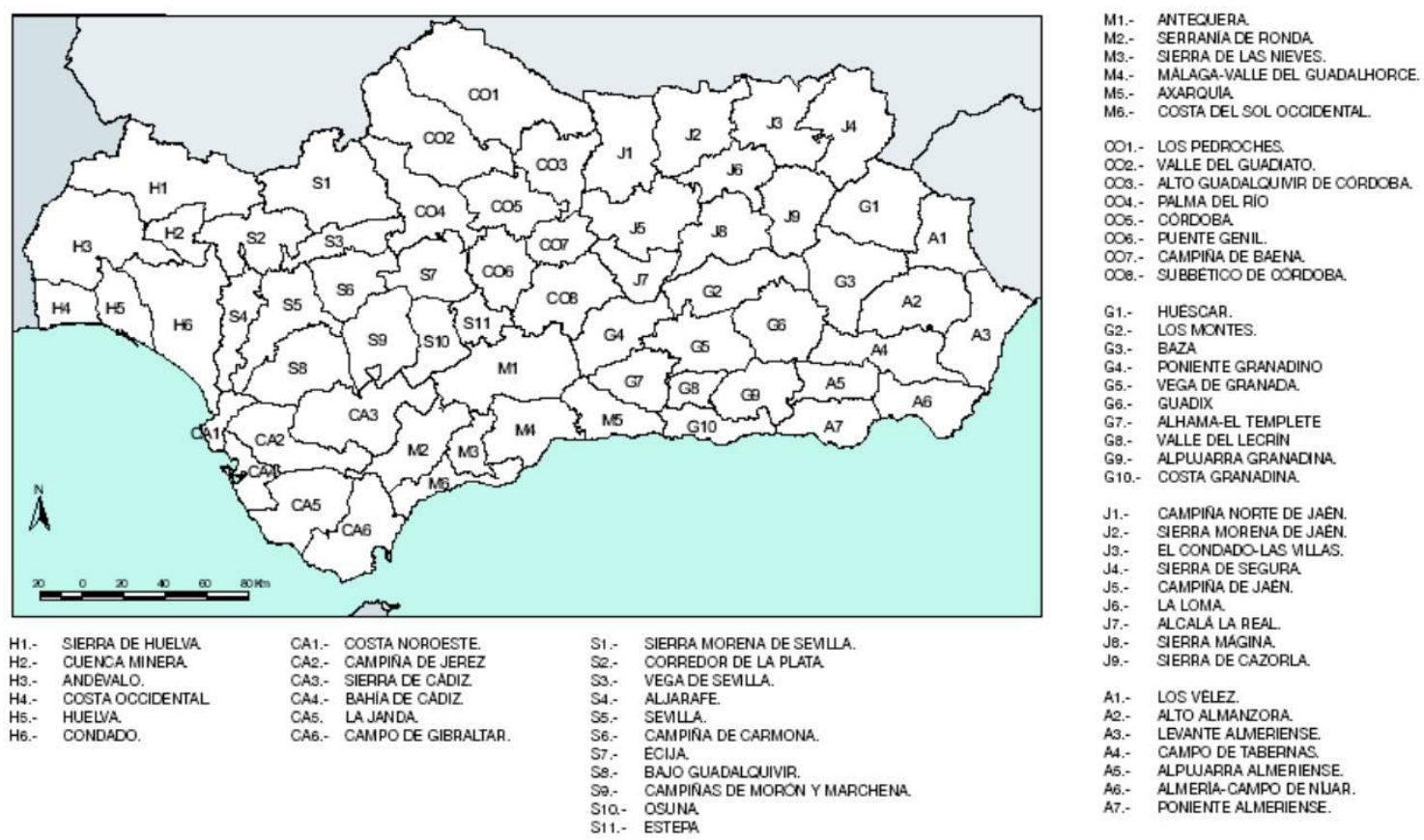

Fuente: ZOIDO, F. y CARAVACA, I. (coordinadores, 2005), Andalucía: segundo Informe de Desarrollo Territorial.

ISSN: 0212-8594 ISSN-e: 2340-2776. № DOI: http://dx.doi.org/10.12795/rea.2013.i30.03

REA 30 (2013):48-77

http://www.publius.us.es/estudios_andaluces 
resultado se obtuvo un mapa de tipologías de desarrollo territorial de escala intermedia.

Por su parte el Grupo de Investigación "Estudios Geográficos Andaluces”, encabezado por el doctor Gabriel Cano, presenta, poco después, Una propuesta de comarcalización para Andalucía (2002), publicada en el tomo X de la obra enciclopédica Conocer Andalucía; donde, por medio de una metodología basada en criterios funcionales, históricos, administrativos, naturales, etc., realiza una delimitación comarcal para todo el territorio andaluz, ajustada a los límites provinciales según determinaba el Estatuto de Autonomía por entonces aún en vigor, y del que exponemos su plasmación espacial, con la información añadida de la población en los municipios andaluces de más 20.000 habitantes en 2005 (figura 6), que hoy en día pueden considerarse, en la práctica, como los verdaderamente urbanos.

Figura 6. Comarcas Conocer Andalucía y población en municipios de más de 20.000 habitantes (2005).

\section{MUNICIPIOS CON MÁS DE 20.000 H., 2005}

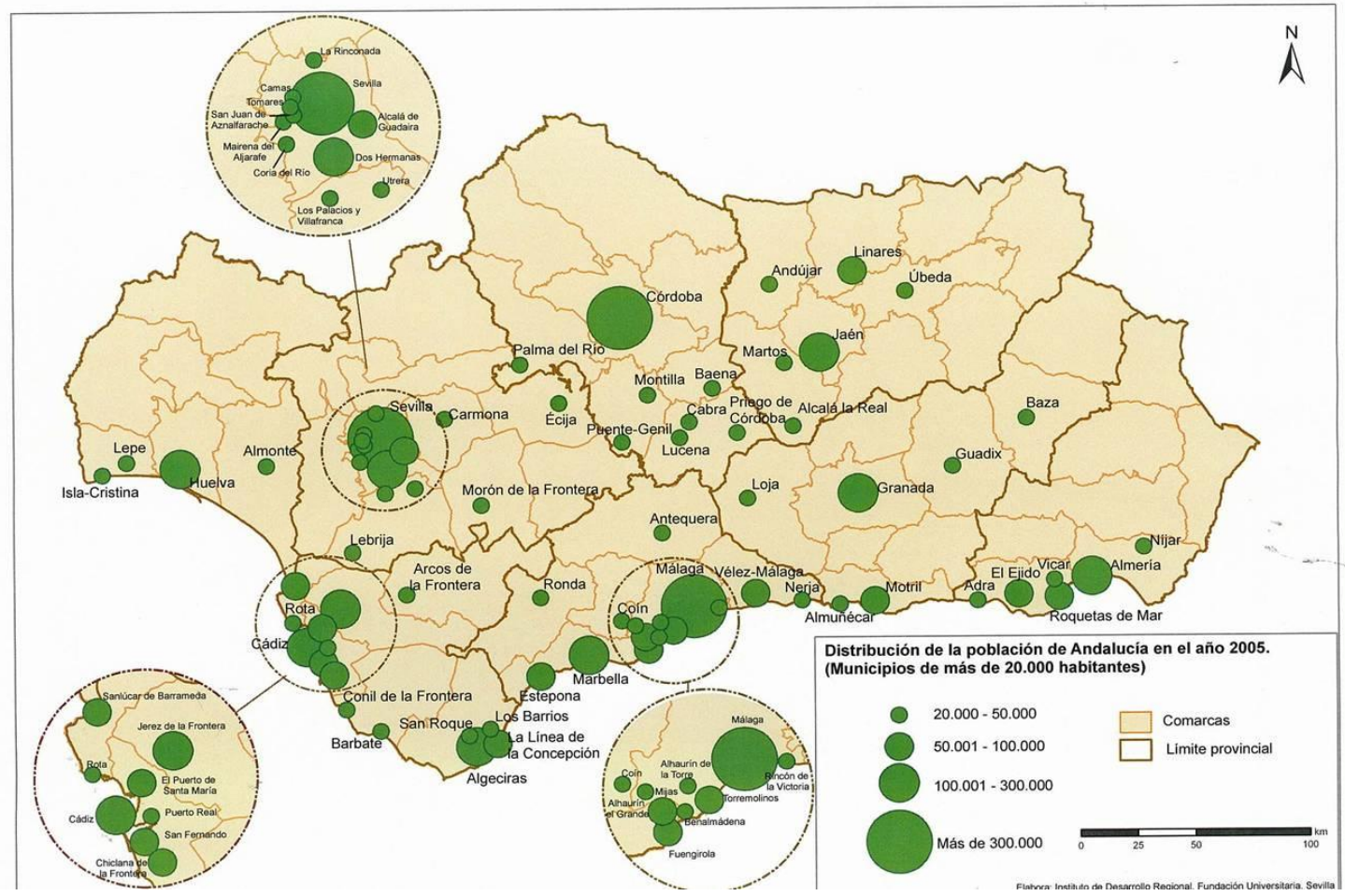

Fuente: Cano García, G. (2006).

ISSN: 0212-8594 ISSN-e: 2340-2776. № DOI: http://dx.doi.org/10.12795/rea.2013.i30.03 
Con posterioridad, en la Reforma del Estatuto de Autonomía andaluz (2007), mucho más extenso que el anterior, se dedica el Título III a estas cuestiones de organización territorial de la Comunidad Autónoma, en el que, entre otros aspectos, se especifica (art. 97) que "la comarca se configura como la agrupación voluntaria de municipios limítrofes con características geográficas, económicas, sociales e históricas afines" y también que "por ley del Parlamento de Andalucía podrá regularse la creación de comarcas, que establecerá, también, sus competencias. Se requerirá en todo caso el acuerdo de los Ayuntamientos afectados y la aprobación del Consejo de Gobierno". Esto es, se sigue insistiendo en una visión integral y tradicional del concepto comarcal, al que no obstante, se le libera por fin del innecesario corsé uniprovincial (recordemos a se insiste en la voluntariedad de pertenencia y en el acuerdo de pertenencia por parte de los ayuntamientos afectados, con lo cual su viabilidad real -aparte de la nula voluntad política para su creación existente en la actualidad- sigue siendo mínima.

De este título estatutario cabe destacar también el artículo 94, dedicado a las agrupaciones de municipios, donde se dice que "una ley regulará las funciones de las I respecto el caso catalán, donde así funcionan desde 1987; Burgueño, 2001); aunque áreas metropolitanas, mancomunidades, consorcios y aquellas otras agrupaciones de municipios que se establezcan, para lo cual se tendrán en cuenta las diferentes características demográficas, geográficas, funcionales, organizativas, de dimensión y capacidad de gestión de los distintos entes locales".

En este sentido recordar que a pesar del referido fracaso del proceso comarcalizador andaluz que tuvo lugar entre 1983 y 1990, distintas circunstancias y necesidades de cooperación intermunicipal condujeron a implementar un proceso espontáneo, esta vez inductivo o bottom-up, que adoptó fórmulas diferentes, pero en el que sobre todo se apostó con claridad por potenciar las figuras de mancomunidades y consorcios, apoyadas en la Ley reguladora de la Demarcación Municipal de Andalucía de 1993.

A modo de ejemplo reflejamos a continuación las "comarcas" de la Iniciativa Comunitaria LEADER y del Programa de Diversificación de las Economías Rurales del Ministerio de Agricultura español que, como se puede apreciar, cubrían la práctica totalidad del territorio andaluz (a excepción de los enclaves estrictamente urbanos y litorales) y que fueron gestionadas (y en algún caso todavía lo son) a través de Grupos de Acción Local y de Desarrollo Rural respectivamente, que utilizan, por regla general, la figura de los consorcios, más flexibles, puesto que en ellos pueden implicarse la iniciativa privada que no tenga ánimo de lucro, y a los que, en determinadas circunstancias establecidas en el artículo 78.3 de la Ley de Autonomía Local de Andalucía (2010), se les llega a considerar como entidades locales.

También han sido lógicamente muy importantes en este proceso de abajo hacia arriba las mancomunidades de municipios, que desde la aprobación de la Ley antes mencionada (LAULA, 2010), ya no sólo pueden estar participadas por ayuntamientos de distintas provincias andaluzas (como la del Bajo Guadalquivir impulsada por Lebrija

ISSN: 0212-8594 ISSN-e: 2340-2776. № DOI: http://dx.doi.org/10.12795/rea.2013.i30.03

REA 30 (2013):48-77

http://www.publius.us.es/estudios_andaluces 
Figura 7. Comarcas LEADER y PRODER en Andalucía.

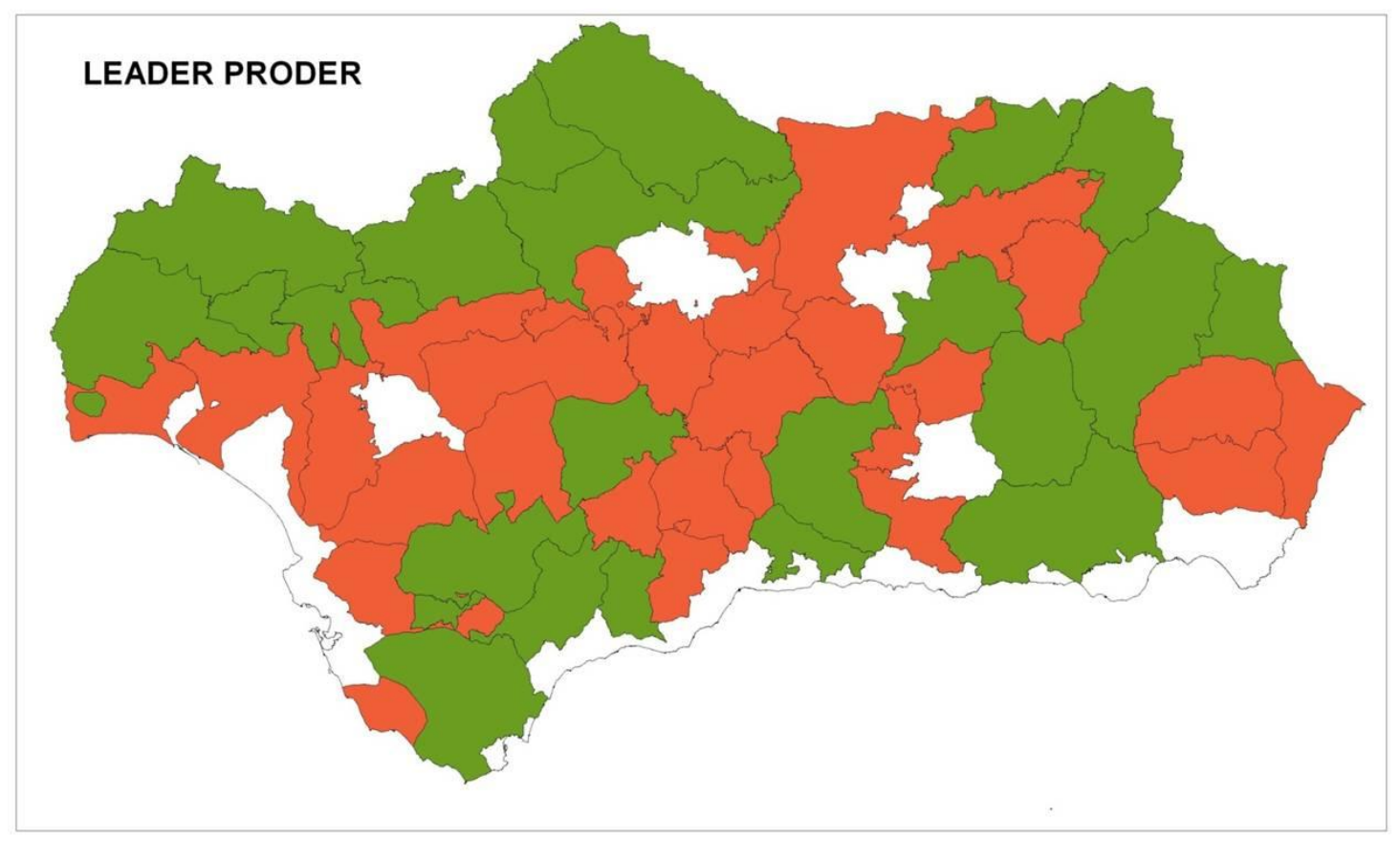

Fuente: Gráfico facilitado por Daniel Montero Cobos ( http://estudiodmc.wordpress.com/ ).

-modelo en muchas ocasiones de desarrollo endógeno- y con presencia de localidades tanto sevillanas como gaditanas), sino que esta opción, con determinadas condiciones, también se amplía a municipios de otras comunidades autónomas.

La LAULA establece asimismo la posibilidad de organizar los términos municipales en circunscripciones territoriales propias con un doble carácter:

- Desconcentradas: Distritos, Barrios, Aldeas, Pedanías y otras denominaciones análogas.

- Descentralizadas: Entidades Vecinales y Entidades Locales Autónomas o EATIMES según la nomenclatura del anteriormente mencionado Registro estatal de Entidades Locales.

Ahora bien, esta nueva norma legislativa andaluza se centra, esencialmente, en la importancia del asociacionismo supramunicipal a través de la potenciación de mancomunidades y consorcios locales, dejando a un lado a las que denominadas agrupaciones de municipios (comarcas y áreas metropolitanas); y todo ello a pesar de que de una simple lectura del nuevo Estatuto (2007) parece deducirse la obligación de la existencia de una Ley que regule a estas últimas, por lo que, una vez derogada la norma de 1993, quedarían en un más que posible "limbo" jurídico, aparte de una escasísima voluntad para su creación administrativa y por tanto política.

ISSN: 0212-8594 ISSN-e: 2340-2776. № DOI: http://dx.doi.org/10.12795/rea.2013.i30.03 


\section{POLÍTICA DE DESARROLLO REGIONAL Y ORDENACIÓN DEL TERRITORIO EN EL MARCO DE LA UNIÓN EUROPEA.}

Si entendemos por POLÍTICA DE DESARROLLO REGIONAL la suma de las actuaciones de la Administración del Estado y de las instituciones de la Unión Europea que se orientan a la disminución de las disparidades entre sus territorios, más las acciones específicas para la potenciación de las estructuras económicas, sociales y espaciales por parte de las distintas regiones, y asumimos la ORDENACIÓN DEL TERRITORIO como aquella política pública destinada a la mejora del orden territorial (disposición espontánea de las variables geográficas sobre el espacio, resultado de la interacción de hechos físicos con elementos humanos), y cuya aplicación debe corresponder a las administraciones regionales (como sucede en España en el caso de las comunidades autónomas), podemos apreciar convergencias entre ambas corrientes interdisciplinares que nos acercan a un concepción integral del DESARROLLO, entendido como la suma de tres pilares fundamentales: un crecimiento económico sostenido (objeto de la política económica), la búsqueda de una equidad o cohesión tanto social como territorial (atendida por una parte por la política social y por otra por la denominada habitualmente en el marco de la Unión Europea como política regional, respectivamente), más la sustentabilidad ecológica (a través de la correspondiente política ambiental) (Márquez, 1998).

Por todo ello no debe extrañarnos que en la actualidad esté cada vez más asumido como indicador de referencia el denominado índice de Desarrollo Humano (HDI en inglés), elaborado desde 1990 por el Programa de las Naciones Unidas para el Desarrollo (UNPD), y que se basa en la consideración equitativa de 3 componentes: el Índice de Esperanza de Vida al nacer (entre 85 y 25 años); el Índice de Educación, que se desglosa en el índice de alfabetización adulta (2/3 del mismo) e índice bruto de matriculación ( $1 / 3$ de éste); y el Índice del Producto Interior Bruto per cápita (entre 40.000 y 100 dólares USA), como consideración sintética de los verdaderos niveles de vida alcanzados, normalmente por un estado. Además, a esta visión socioeconómica, cabe añadir, en especial en los últimos años, la perspectiva del desarrollo sostenible, surgido a raíz del Informe Brundtland de la Comisión Mundial sobre el Medio Ambiente y el Desarrollo (Naciones Unidas, 1987), y que lo entiende como aquél que cubre las necesidades actuales sin comprometer las posibilidades de las generaciones futuras para satisfacer las suyas propias.

En la Unión Europa, como proyecto de construcción interestatal a la que recientemente se le ha concedido el Premio Nobel de la Paz (2012), estas cuestiones se resuelven el marco de sus diferentes demarcaciones administrativas, jerarquizadas en 3 niveles con distintas repercusiones en las relaciones entre ellos. Así los NUTs I son por lo general grandes paquetes espaciales que incluso pueden llegar a afectar al conjunto del estado (como sucede en Portugal), y que el caso de España derivan de la

ISSN: 0212-8594 ISSN-e: 2340-2776. № DOI: http://dx.doi.org/10.12795/rea.2013.i30.03

REA 30 (2013):48-77

http://www.publius.us.es/estudios_andaluces 
Figura 8. NUTs I en la Unión Europea de 15 miembros y estados incorporados con posterioridad.

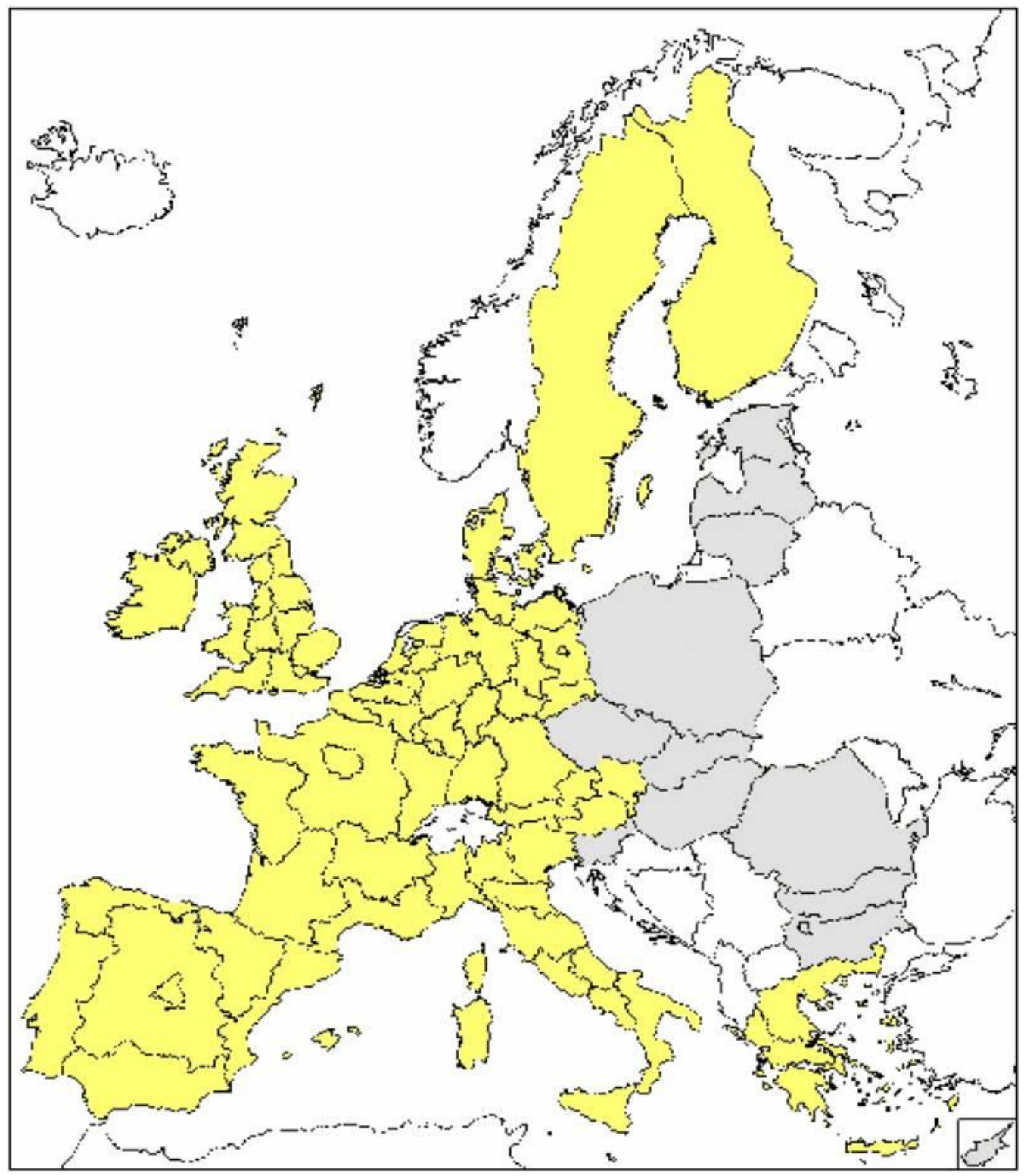

Fuente: Gráfico facilitado por Jesús Gabriel Moreno Navarro ( http://personal.us.es/jgamore/ ).

adición de varias comunidades autónomas con base territorial común, habitualmente física. Sin embargo su grado de repercusión en la Política Regional comunitaria es menguado, y quizás sólo entran en consideración en relación con la Estrategia Territorial Europea (ETE) como plasmación del intento por establecer una Ordenación del Territorio europeo de carácter conjunto.

Sin embargo serán los NUTs de nivel II los que tradicionalmente han tenido verdadera incidencia en la Política Regional de la Unión Europea. Así, en el actual período de

ISSN: 0212-8594 ISSN-e: 2340-2776. № DOI: http://dx.doi.org/10.12795/rea.2013.i30.03 REA 30 (2013):48-77 
Figura 9. NUTs I en la Unión Europea de 15 miembros y en los 12 incorporados con posterioridad.

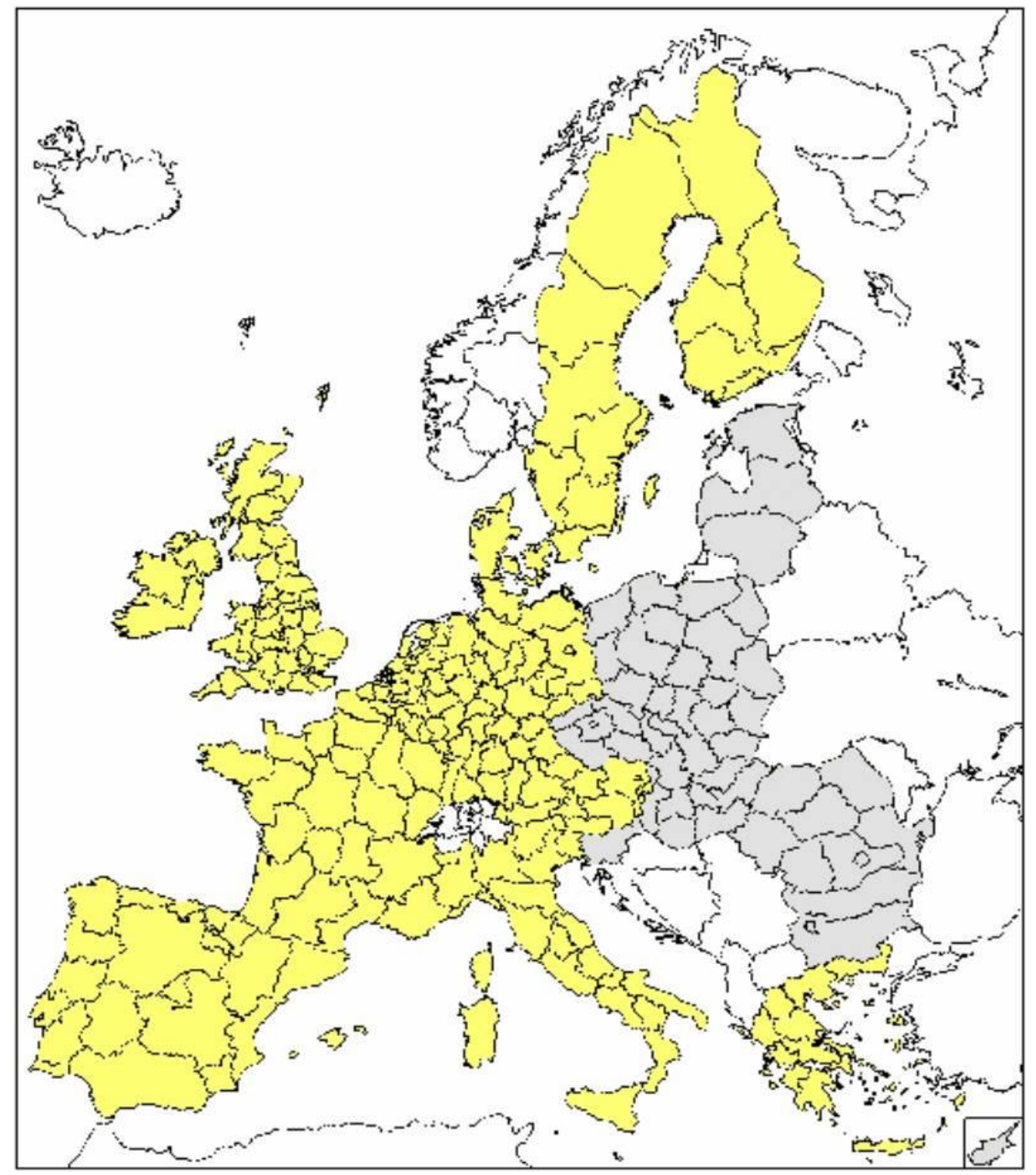

Fuente: Gráfico facilitado por Jesús Gabriel Moreno Navarro ( http://personal.us.es/jgamore/ ).

programación económica se distingue entre regiones de "convergencia" (aquéllas que por lo general su renta per cápita no supera al $70 \%$ de la media comunitaria) y las restantes, calificadas como de "competitividad y empleo". Son obviamente las primeras, denominadas con anterioridad regiones de objetivo no. 1, las que son objeto de atención preferente por parte de los distintos fondos e instrumentos comunitarios al respecto de estas cuestiones. Como era previsible, tras la ampliación de la UE por el Este, incorporando estados de antigua economía planificada del bloque comunista, España no sólo va a ver reducidos sus niveles de ingresos, sino que sus territorios

ISSN: 0212-8594 ISSN-e: 2340-2776. № DOI: http://dx.doi.org/10.12795/rea.2013.i30.03 REA 30 (2013):48-77 
afectados (CC.AA.) son sustancialmente menos que en la etapa precedente. Para mitigar el grado de impacto de estas nuevas circunstancias se han establecido medidas tales como la catalogación de regiones que se encuentran en fase de salida de este tipo de "convergencia", así como otras que están en situación de entrada en la categoría de "competitividad y empleo", lo que en la práctica implica la consideración de 4 niveles de gradación en la Política Regional europea.

Figura 10. NUTs II de la Unión Europea diferenciando entre regiones de convergencia y regiones de competitividad y empleo.

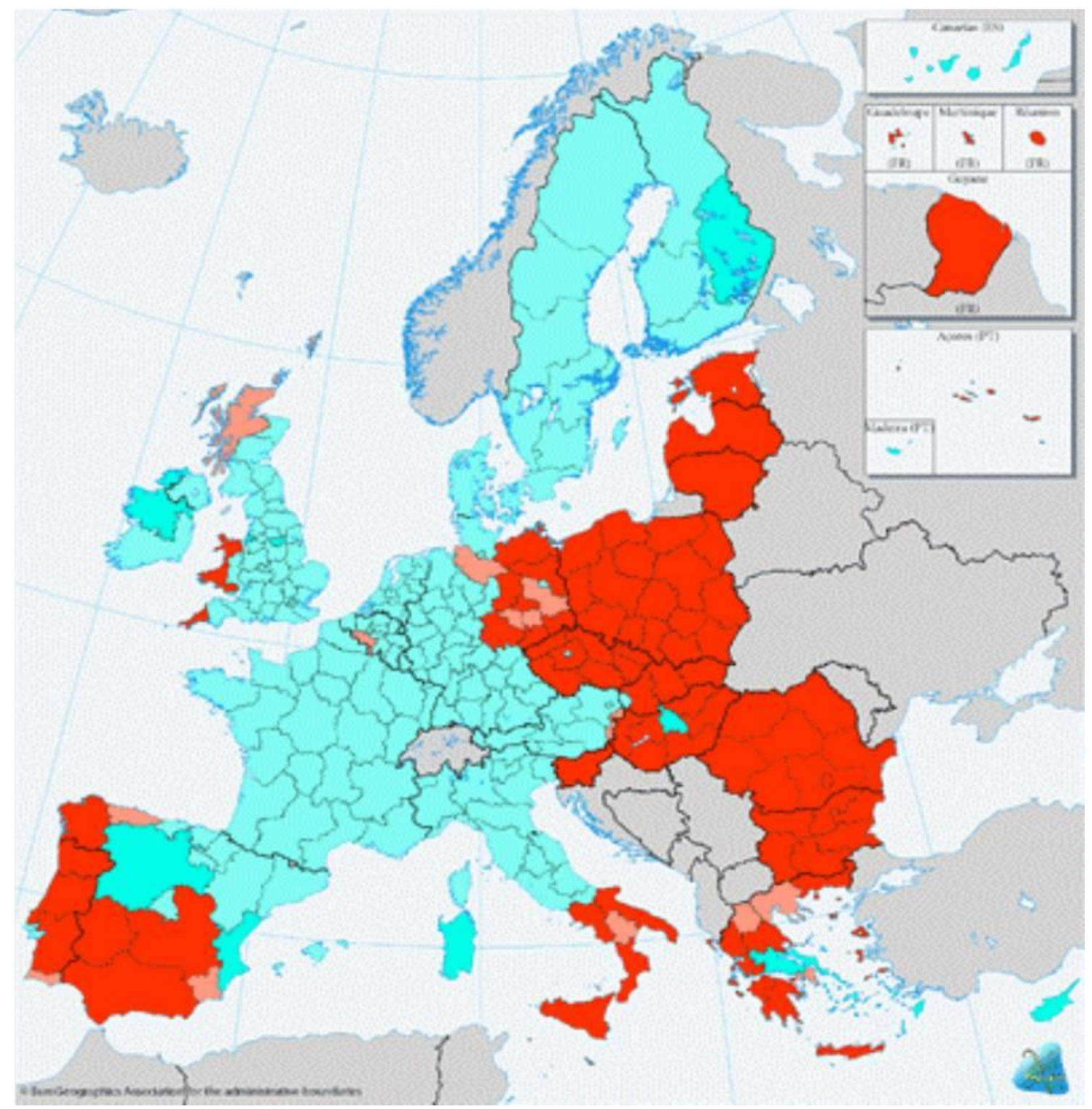

Fuente: Política Regional de la Unión Europea, http://ec.europa.eu/regional_policy/index_pl.cfm

ISSN: 0212-8594 ISSN-e: 2340-2776. № DOI: http://dx.doi.org/10.12795/rea.2013.i30.03 REA 30 (2013):48-77 
Mucho menos peso tienen los NUTs III, verdadero enjambre territorial como se puede apreciar en la figura 11, y que en el caso español se corresponden con nuestra red de 50 provincias. Se utilizan sobre todo para la cooperación transfronteriza, tanto entre estados miembros de la Unión como de éstos con países externos a la misma, bien sean candidatos a la incorporación o pertenezcan a los que, como veremos más adelante, forman parte de la política europea de vecindad (PEV). Esta cuestión transfronteriza se aborda ahora dentro la Política Regional, pero es heredera directa de la antigua Iniciativa Comunitaria INTERREG en sus sucesivas etapas. España tiene lógicamente proyectos tanto con la república francesa como portuguesa, como estados miembros de la Unión, pero también con el Reino de Marruecos a través de distintas provincias andaluzas: Almería, Granada, Málaga, Cádiz y Huelva (esta última partícipe asimismo de proyectos con el Algarve y el Alentejo portugueses). Llama sobre todo la atención que la contraparte marroquí corresponde ahora al conjunto de las

Figura 11. NUTs I en la Unión Europea de 15 miembros y en los 12 incorporados con posterioridad.

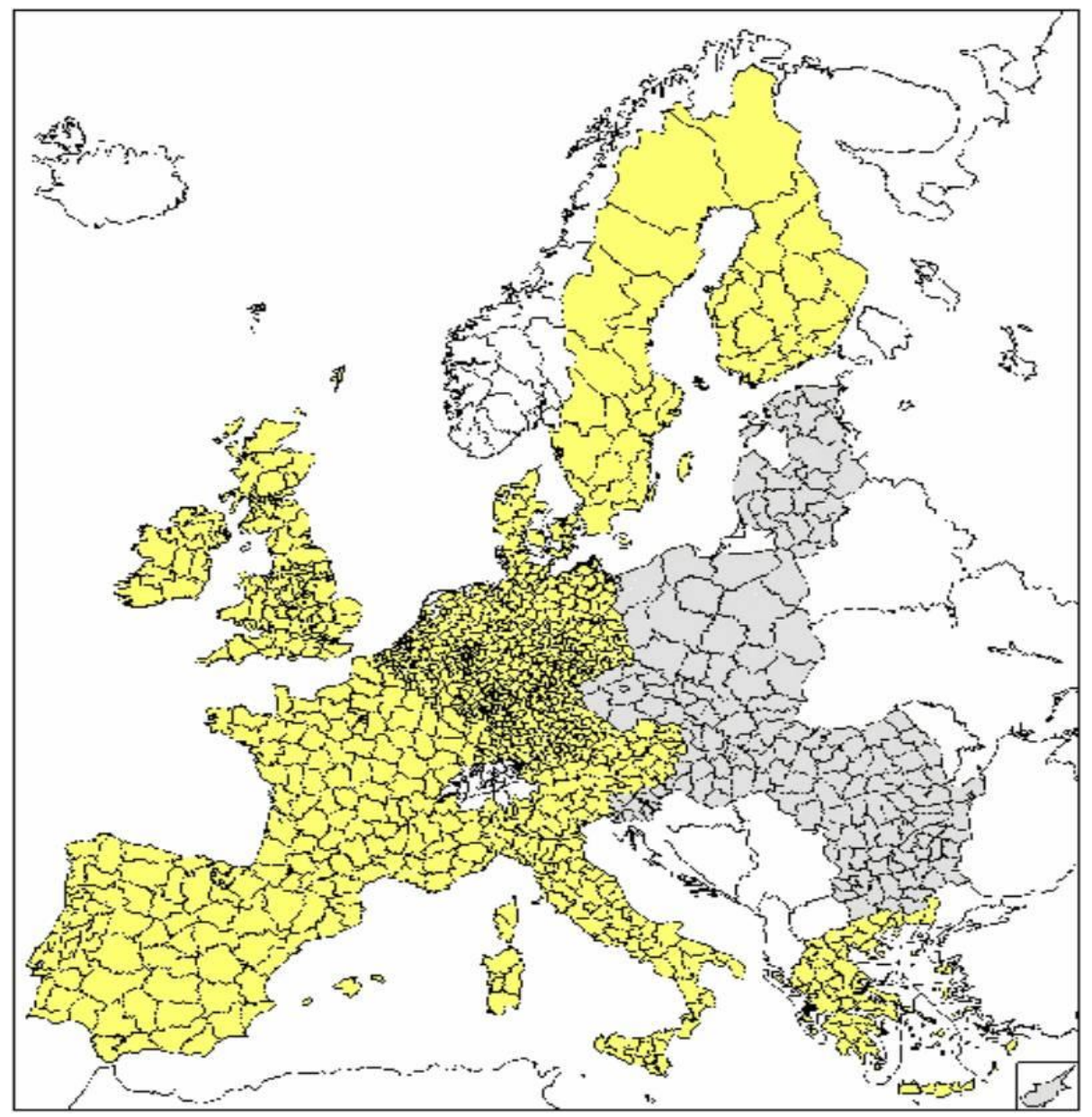

Fuente: Gráfico facilitado por Jesús Gabriel Moreno Navarro (http://personal.us.es/jgamore/ ).

ISSN: 0212-8594 ISSN-e: 2340-2776. № DOI: http://dx.doi.org/10.12795/rea.2013.i30.03 REA 30 (2013):48-77

http://www.publius.us.es/estudios_andaluces 
regiones del Norte de este país (más allá del antiguo protectorado español, fundamentalmente rifeño), llegando a afectar casi toda su frontera con Argelia, ya que la parte septentrional se acerca a la meridional en función de la posibilidad de cooperación entre Canarias (España) con el Sur marroquí y también con el Norte del antiguo Sahara Occidental español, territorio que sí se contempla a estos efectos.

Todas estas cuestiones han sido ya objeto de atención científica-académica, y en este sentido cabe resaltar la realización del Congreso Internacional Cooperación Transfronteriza Andalucía-Algarve-Alentejo, celebrado en Huelva en 2009 (Márquez, J.A., coordinador, 2011), donde no sólo se abordaron las relaciones en este ámbito del Suroeste europeo, sino también en otros puntos de la frontera con Portugal e incluso con el Norte marroquí (Ventura y Moreno, 2011). La frontera húmeda, del Bajo Guadiana, se ha tratado también de forma específica (Márquez, J.A., director, 2012); y, por supuesto, el conjunto de los proyectos de cooperación que se han llevado a cabo con el Norte de Marruecos (Iglesias, M., coordinadora, y otros, 2011).

Figura 12. Actuales programas de cooperación transfronteriza de la Unión Europea entre estados miembros y algunos de sus fronteras exteriores.

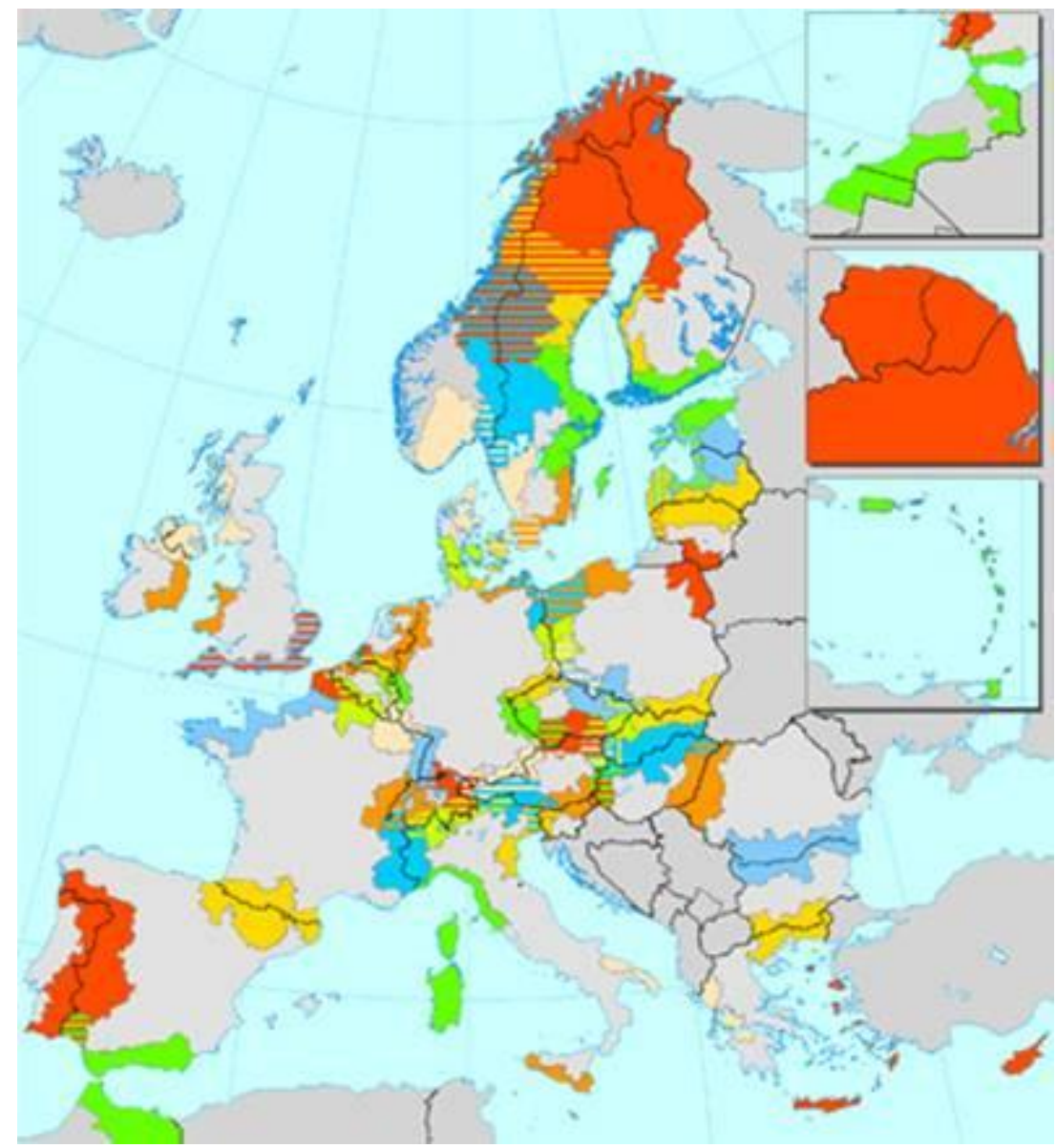

Fuente: Política Regional de la Unión Europea, http://ec.europa.eu/regional_policy/index_pl.cfm

ISSN: 0212-8594 ISSN-e: 2340-2776. № DOI: http://dx.doi.org/10.12795/rea.2013.i30.03 REA 30 (2013):48-77

http://www.publius.us.es/estudios_andaluces 
También se consideran en la actualidad como parte de la Política Regional de la Unión a los denominados Programas Transnacionales, reflejados en la figura 13, y que en nuestra opinión enlazan directamente con los proyectos de construcción de macrorregiones europeas más allá de las fronteras interestatales de los estados miembros, máxima expresión a su vez de la referida Estrategia Territorial Europea (ETE), y que tienen una sólida base conceptual en estudios previos, impulsados en muchos casos desde el ámbito científico de la Geografía.

Llama la atención, además del exotismo que supone el establecer lazos con espacios geográficos muy alejados en función de los territorios de ultramar de la UE (como sucede en el área del Caribe o del Océano Índico), el que se intente involucrar a estados no miembros pero obviamente pertenecientes al espacio europeo, como son los casos de Noruega, Suiza, estados balcánicos de la antigua Yugoeslavia, Albania, Bielorrusia, Moldavia y otros espacios adyacentes del mundo eslavo.

Igualmente resulta interesante el que éstas sean áreas a las que no se considera como meras piezas territoriales que engarzan entre ellas como si se tratara de un puzle, sino que se asume que la realidad espacial es compleja y dinámica, admitiéndose solapamientos entre estos programas. Así, por ejemplo, en el caso de España, observamos cómo toda la Península y Baleares está incluida dentro del Suroeste de Europa junto con el Portugal continental y el Macizo Central o de Aquitania francés (ámbito muy próximo, por tanto, a la denominada Diagonal Continental en otros estudios espaciales), pero también nos vemos afectados por la Costa Atlántica (Arco Atlántico en otros trabajos), y por el área Mediterránea (también denominada Arco Latino o Norte del Sur), en estos dos últimos casos de manera evidentemente parcial dentro del conjunto del estado español.

Resulta interesante además que sea Andalucía, la región continental más meridional de toda la Unión, en la que coincidan las tres áreas referidas que afectan a España, si bien en el caso de la Costa Atlántica obviamente no en su totalidad, sino sólo a través de las provincias de Huelva, Sevilla y Cádiz. Estas cuestiones se retomarán más adelante al comentar las perspectivas futuras de cooperación interregional.

\section{SITUACIÓN ACTUAL Y PERSPECTIVAS DE FUTURO.}

Para abordar la situación actual y a medio plazo de la cooperación interterritorial en nuestro entorno, vamos a plantear dos escalas de trabajo: la internacional, a la que se incorpora España como estado soberano; y la regional andaluza dentro del estado español, ya que esta temática está descentralizada en nuestras comunidades autónomas, y debido, por supuesto, a la conocida posición geoestratégica, geoeconómica y geopolítica excepcional de Andalucía a nivel mundial.

En relación con el primer escalón, el que afecta a las relaciones internacionales, vamos a destacar tres actuaciones en orden cronológico de aparición:

ISSN: 0212-8594 ISSN-e: 2340-2776. № DOI: http://dx.doi.org/10.12795/rea.2013.i30.03

REA 30 (2013):48-77

http://www.publius.us.es/estudios_andaluces 
Figura 13.- Actuales programas transnacionales de la Unión Europea.

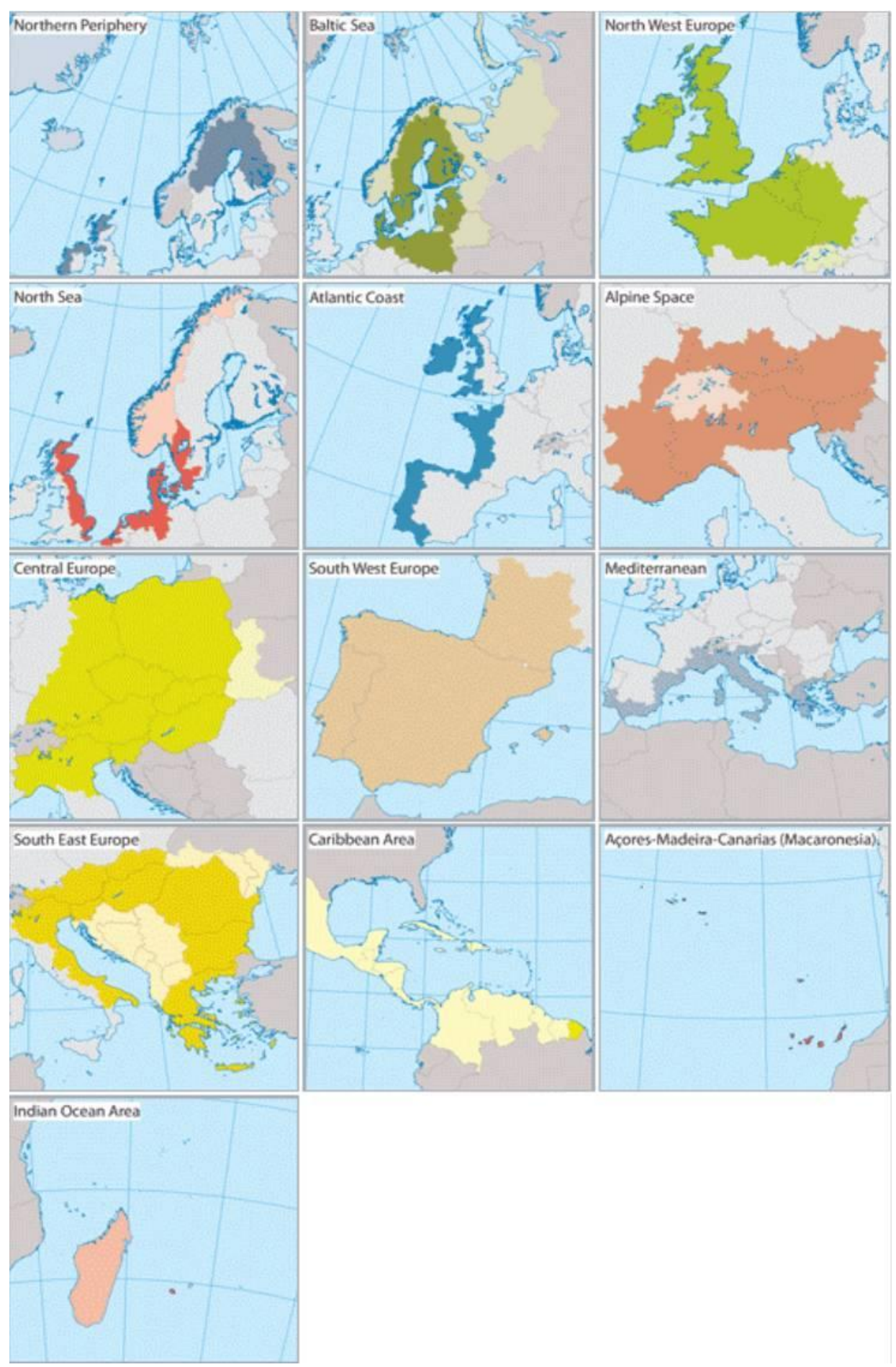

Fuente: Política Regional de la Unión Europea, http://ec.europa.eu/regional_policy/index_pl.cfm

ISSN: 0212-8594 ISSN-e: 2340-2776. № DOI: http://dx.doi.org/10.12795/rea.2013.i30.03 REA 30 (2013):48-77 


\section{- Fundación Tres Culturas del Mediterráneo.}

El Reino de Marruecos y la Junta de Andalucía decidieron, en 1998, crear un foro que, basado en los principios de la paz, el diálogo y la tolerancia, promoviera el encuentro entre pueblos y culturas del Mediterráneo. A esta iniciativa se adhiere con posterioridad el Centro Simon Peres por la Paz, la Autoridad Nacional Palestina, y otras personas e instituciones de Israel comprometidas con el diálogo y la paz.

Así, el día 8 de marzo de 1999 se constituye, en la ciudad de Sevilla, la Fundación Tres Culturas del Mediterráneo. Las características singulares, y en cierto modo excepcionales, de esta Fundación la convierten en referente de tolerancia y progreso. Existen pocas fundaciones en el mundo con una presencia plurinacional tan representativa y equilibrada entre sus miembros, con una vinculación tan particular con el ámbito mediterráneo y con tal vocación de apertura hacia los países ribereños.

El espíritu de esta Fundación es también reflejo de la Conferencia Euromediterránea de Barcelona, celebrada en noviembre de 1995, que propuso un nuevo horizonte para el conjunto de la cuenca mediterránea: el establecimiento de una zona de paz, estabilidad y progreso en ambas orillas de un mar que ha sido cuna de civilizaciones.

La cooperación en el Mediterráneo tiene hoy más importancia que nunca y, por ello, la creciente cooperación Andalucía-Marruecos constituye uno de los ejes básicos de actuación de la Fundación.

\section{- Política Europea de Vecindad (PEV).}

La PEV se ha desarrollado en el contexto de la ampliación de la UE en 2004, con el objetivo de evitar la aparición de nuevas líneas divisorias entre la UE ampliada y nuestros vecinos, y de consolidar la estabilidad y la seguridad y el bienestar para el conjunto regional, de manera que también aborda objetivos establecidos en la Estrategia Europea de Seguridad.

Fue esbozada en una Comunicación de la Comisión sobre Una Europa más amplia en marzo de 2003, a la que siguió un Documento Estratégico, más elaborado, sobre la Política Europea de Vecindad, publicado en mayo de 2004. Este documento expone, en términos concretos, el modo en que la UE propone trabajar estrechamente con estos países.

La UE ofrece a nuestros vecinos una relación privilegiada, creando un compromiso mutuo con los valores comunes (democracia y derechos humanos, estado de derecho, buen gobierno, principios de economía de mercado y desarrollo sostenible). Va más allá de las relaciones existentes para ofrecer una relación política y una integración económica más profundas. El grado de ambición de la relación dependerá de hasta qué punto se comparten estos valores. La PEV es distinta del proceso de ampliación,

ISSN: 0212-8594 ISSN-e: 2340-2776. № DOI: http://dx.doi.org/10.12795/rea.2013.i30.03 REA 30 (2013):48-77

http://www.publius.us.es/estudios_andaluces 
pues no prejuzga la relación que los vecinos europeos pueden desarrollar con la UE en un futuro.

Concierne a los países inmediatos con fronteras terrestres o marítimas: Argelia, Armenia, Azerbaiyán, Bielorrusia, Egipto, Georgia, Israel, Jordania, Líbano, Libia, Moldavia, Marruecos, Autoridad Nacional Palestina, Siria, Túnez y Ucrania; aunque Rusia también es un estado próximo a la UE, las relaciones con la Federación rusa se desarrollan mediante una Asociación Estratégica.

- Alianza de Civilizaciones.

La Alianza de Civilizaciones fue presentada por el ex-presidente del Gobierno de España, José Luis Rodríguez Zapatero (PSOE), en septiembre de 2004, durante el 590 Período de Sesiones de la Asamblea General de las Naciones Unidas. Con posterioridad, el Primer Ministro de Turquía se adhirió a la iniciativa como copatrocinador. Asumida formalmente por el Secretario General de Naciones Unidas el 14 de julio de 2005, la Alianza es desde entonces una iniciativa del Secretario General.

El sentido de la iniciativa de la Alianza de Civilizaciones no es enteramente nuevo. El ya referido Proceso Euromediterráneo de Barcelona (1995), en el marco de la Unión Europea, constituye un primer ejemplo de puesta en práctica de los principios que inspiran la iniciativa de la Alianza de Civilizaciones.

La Alianza de Civilizaciones ha trasladado ese ejercicio de reflexión y de diseño de acciones prácticas a un foro de ámbito universal y dotado de un mandato y una legitimidad insustituibles para afrontar estas cuestiones: la Organización de las Naciones Unidas.

Hasta el lanzamiento de esta iniciativa, el tema había sido abordado con un enfoque teórico. Sin embargo era necesario dar pasos orientados hacia la acción común. La Alianza de Civilizaciones quiere centrarse en la dimensión política, facilitando la elaboración de recomendaciones prácticas y asumibles por los gobiernos, las organizaciones internacionales y la sociedad civil en su conjunto.

El nuevo Presidente del Gobierno español Mariano Rajoy (PP) ha ratificado recientemente ante las Naciones Unidas (octubre de 2012) el compromiso de España por seguir participando de manera activa en este proyecto internacional impulsado por el gobierno anterior.

A escala regional andaluza cabe diferenciar entre determinaciones recogidas en el Plan de Ordenación del Territorio de Andalucía y las que derivan de la elaboración de los distintos planes subregionales que al respecto de este tema se están elaborando. 


\section{- Plan de Ordenación del Territorio de Andalucía (2006).}

Éste se aprobó finalmente mediante el Decreto 206/2006, y tiene como finalidad general definir la organización física espacial para las funciones territoriales de Andalucía, adecuadas a sus necesidades y potencialidades actuales y diseñar una estrategia territorial andaluza global, para garantizar el fin de los desequilibrios internos y asegurar una adecuada conexión del territorio regional con el exterior.

El Modelo Territorial propuesto aporta una zonificación interna en distintas unidades que son el resultado de la integración de diversos referentes considerados: las ciudades y los asentamientos junto con sus estructuras y redes, los ejes de articulación física regional, y la base natural y patrimonial. Se establecen una serie de sistemas y redes de asentamientos que organizan ámbitos territoriales en función de la influencia o atracción que ejercen sus centros poblacionales, obteniéndose así un sistema polinuclear de centros regionales, redes de ciudades medias, y asentamientos en áreas rurales.

Además se diseñan las denominadas unidades territoriales, que son áreas continuas, definidas por su homogeneidad física y funcional, así como por presentar problemas y oportunidades comunes en materias relacionadas con el uso económico del territorio y la gestión de sus recursos patrimoniales. Se trata de referentes básicos para el desarrollo de estrategias territoriales en una doble orientación: por un lado como modelos específicos de gestión del uso del suelo y de utilización de los recursos naturales, el paisaje o la prevención de riesgos, y por otro como ámbitos en los que contextualizar los grandes sistemas regionales (ciudades, transportes, hidráulico, energético y patrimonial).

Esta característica, eminentemente funcional y vertebradora del territorio, permite que la delimitación de unidades territoriales sea novedosa, ya que encontramos casos cuyos límites no se ajustan a las fronteras administrativas provinciales o municipales, siendo posible la integración de territorios con fuertes vinculaciones e identidades propias a pesar de su pertenencia a provincias distintas.

De gran interés resulta la inserción de Andalucía con su entorno regional, apreciándose por un lado su interpretación como gozne de unión entre el Arco Atlántico y la región Euromediterránea (central y occidental), participando ahora sus 8 provincias por igual de esta concepción y lanzando puentes tanto hacia el corredor atlántico marroquí (eje Tánger-Casablanca, muy dinámico), como por el montañoso Norte rifeño hasta la frontera con Argelia (bastante deprimido). Ya en las Bases y Estrategias (1999) previas a la elaboración de este Plan, al plantear la integración exterior de la Comunidad andaluza, se mencionaba el Nodo estratégico del Estrecho, así como los corredores con el resto de comunidades autónomas limítrofes y con la capital del estado (Madrid), más la potenciación de los vínculos con el Algarve portugués. Todos estos aspectos se pueden visualizar a través de las figuras 16 y 17.

ISSN: 0212-8594 ISSN-e: 2340-2776. № DOI: http://dx.doi.org/10.12795/rea.2013.i30.03 
Figura 14. Modelo Territorial establecido en el POTA (2006).

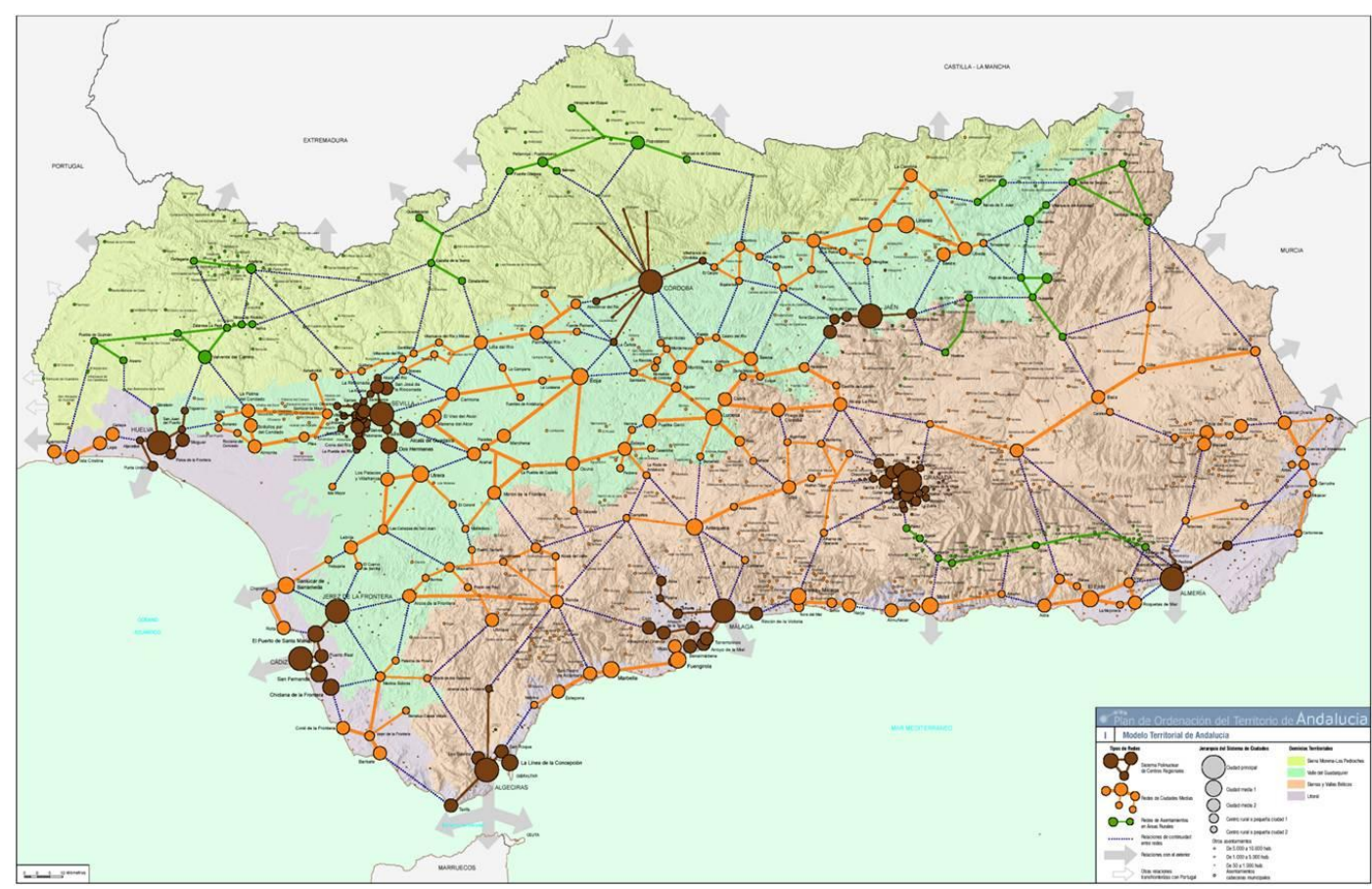

Fuente: Plan de Ordenación del Territorio de Andalucía, Decreto 206/2006, de 28 de noviembre, de la Consejería de Obras Públicas y Transportes de la Junta de Andalucía.

Figura 15. Unidades territoriales propuestas en el POTA (2006).

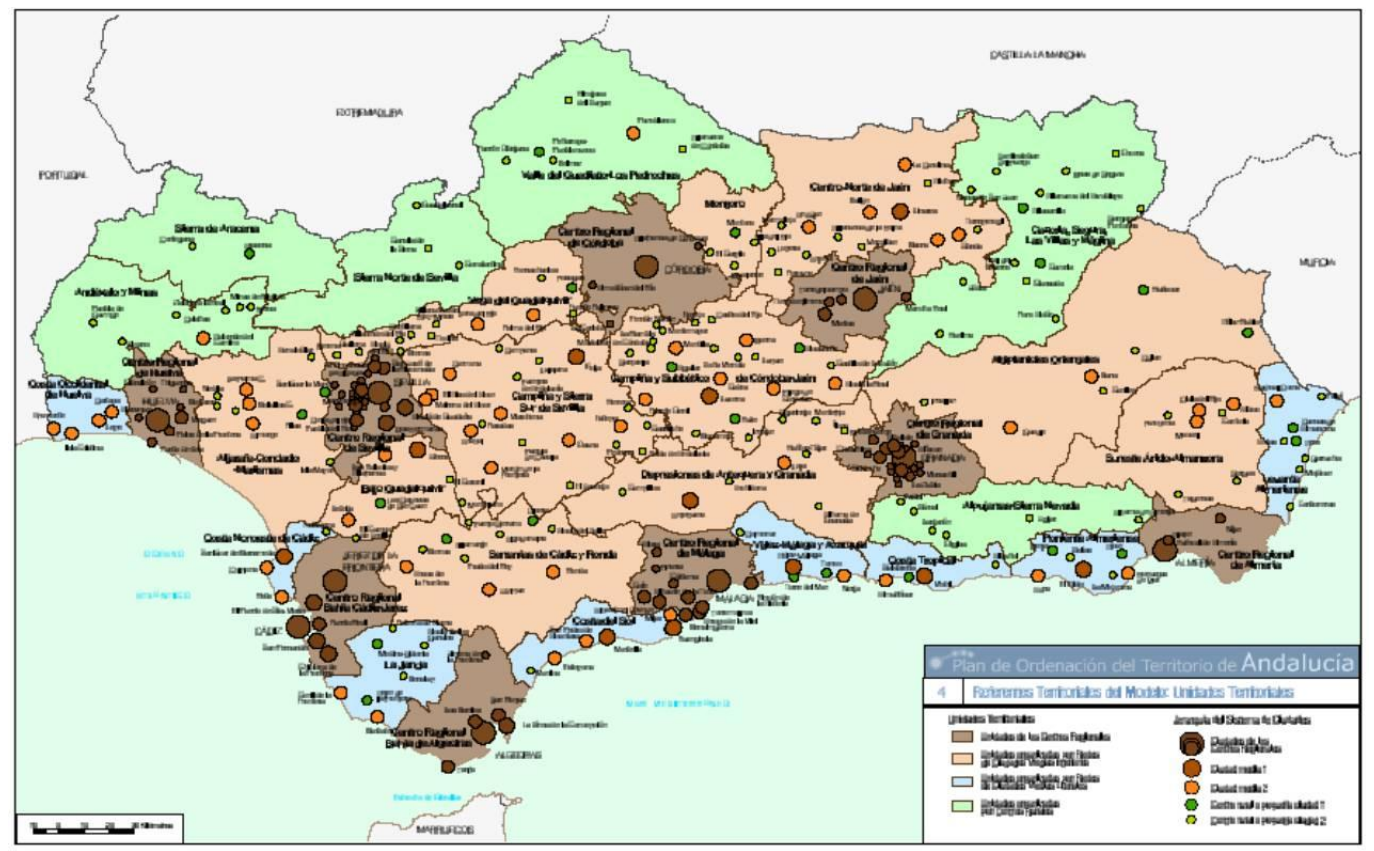

Fuente: Plan de Ordenación del Territorio de Andalucía, Decreto 206/2006, de 28 de noviembre, de la Consejería de Obras Públicas y Transportes de la Junta de Andalucía.

ISSN: 0212-8594 ISSN-e: 2340-2776. № DOI: http://dx.doi.org/10.12795/rea.2013.i30.03 REA 30 (2013):48-77

http://www.publius.us.es/estudios_andaluces 
Figura 16. Integración de Andalucía con su entorno regional según el POTA (2006).

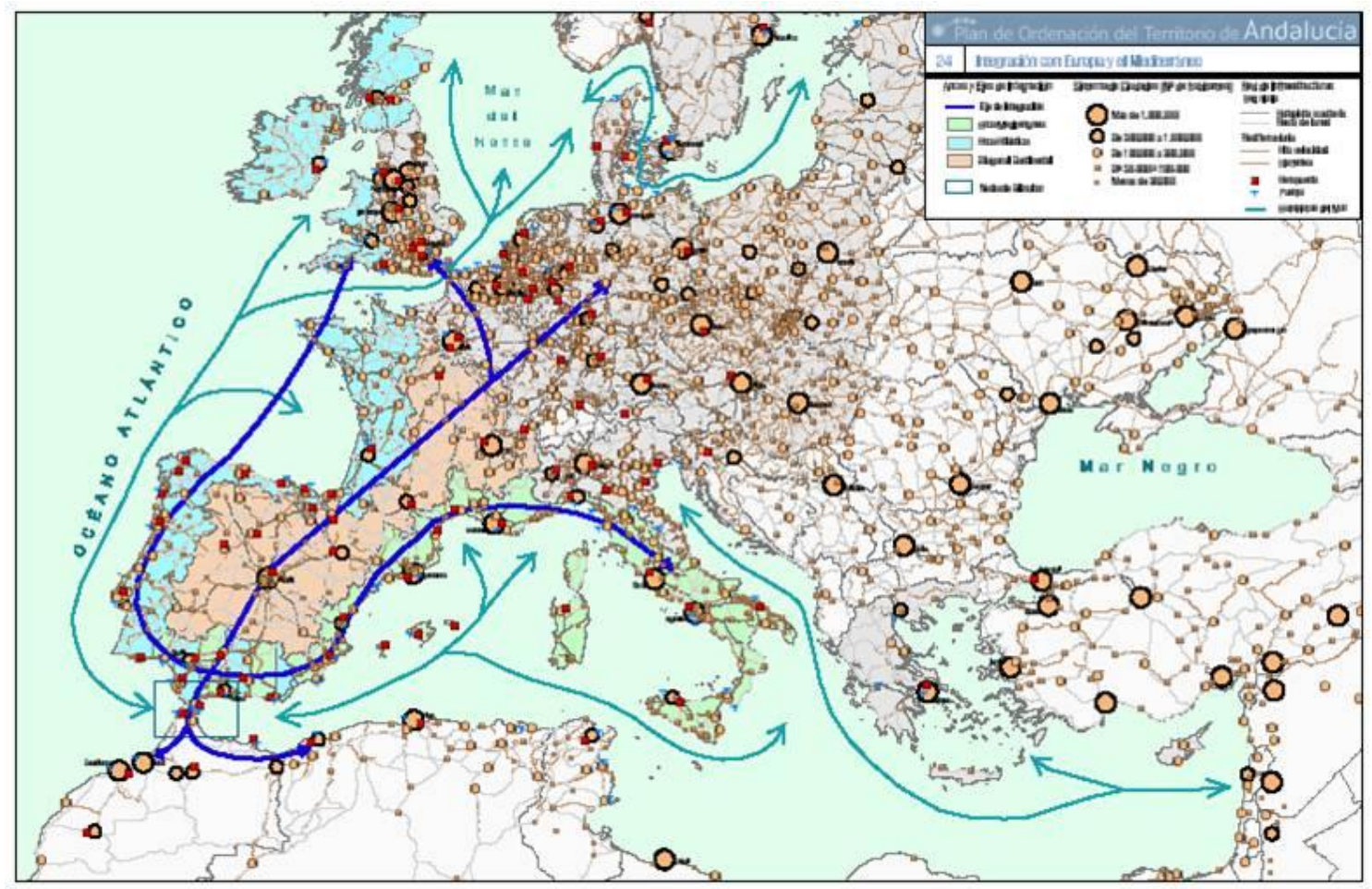

Fuente: Plan de Ordenación del Territorio de Andalucía, Decreto 206/2006, de 28 de noviembre, de la Consejería de Obras Públicas y Transportes de la Junta de Andalucía.

- Planes de Ordenación del Territorio de ámbito subregional en Andalucía.

Por su parte los Planes de Ordenación del Territorio de ámbito subregional son instrumentos derivados del POTA (2006) que tienen como misión principal el establecimiento de los elementos básicos para la organización y estructura del territorio, sirviendo, en su ámbito, de marco de referencia para el desarrollo y coordinación de las políticas, planes, programas y proyectos de las administraciones y entidades públicas, así como de las actividades de los particulares.

Los planes son formulados por el Consejo de Gobierno, a propuesta en la actualidad de la Consejería de Agricultura, Pesca y Medio Ambiente de la Junta de Andalucía, o a instancia de las corporaciones locales, en cuyo caso la iniciativa deberá ser refrendada, al menos, por los tres quintos de los municipios incluidos en el ámbito del plan. Esto último es de gran interés, puesto que permite a las entidades locales agruparse territorialmente y no depender en exclusiva de las decisiones que emanen del poder autonómico, cuestión importante, sobre todo, para los amplios espacios que aún quedan por definir para este tipo de planificación territorial.

ISSN: 0212-8594 ISSN-e: 2340-2776. № DOI: http://dx.doi.org/10.12795/rea.2013.i30.03

REA 30 (2013):48-77

http://www.publius.us.es/estudios_andaluces 
Figura 17. Integración exterior de Andalucía con sus vecinos.

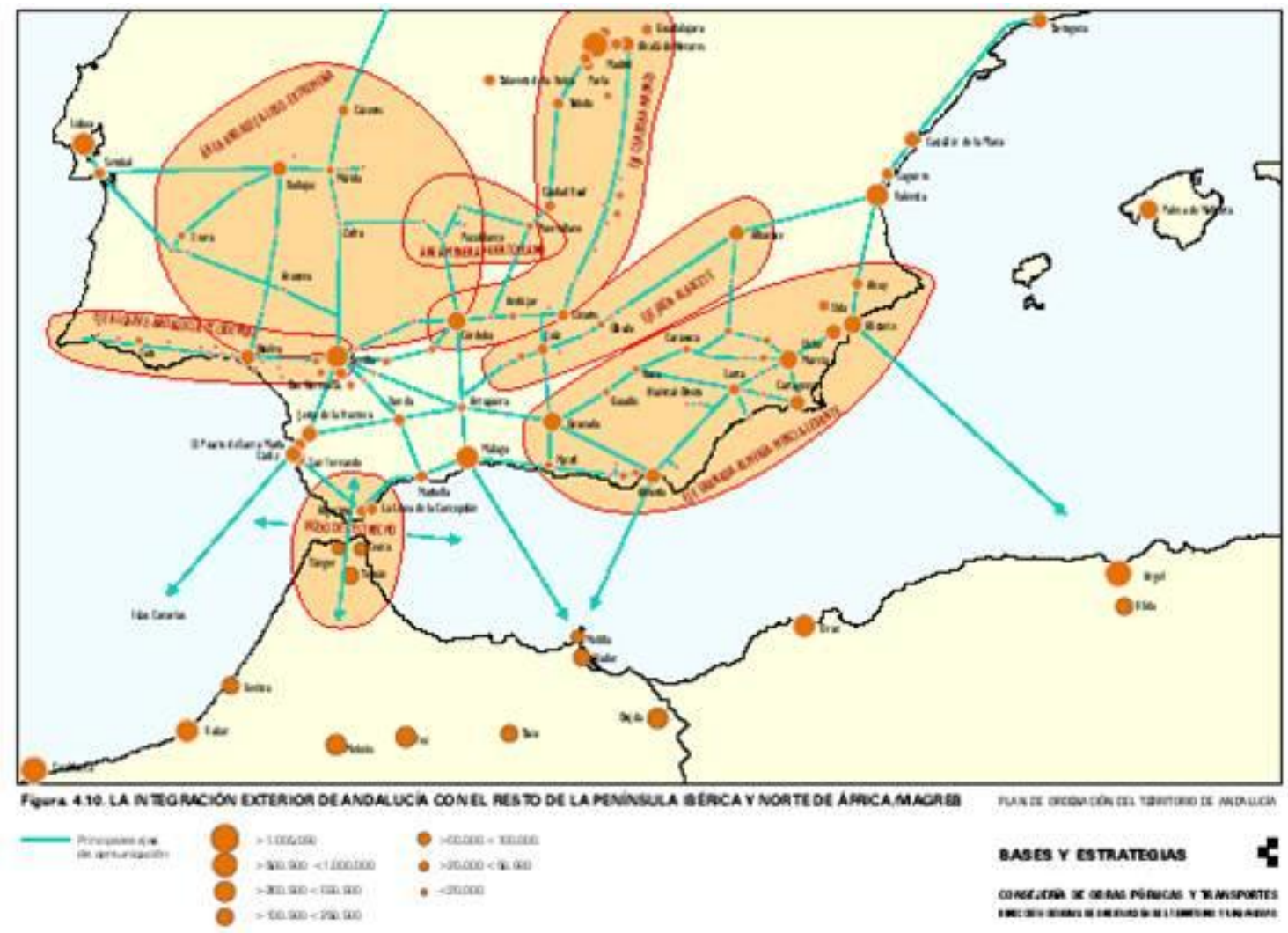

Fuente: CONSEJERÍA DE OBRAS PÚBLICAS Y TRANSPORTES (1999), Bases y Estrategias del Plan de Ordenación del Territorio de Andalucía, Sevilla, Junta de Andalucía.

En la práctica, su elaboración no se está ajustando a los límites de las unidades territoriales del POTA como inicialmente estaba previsto, según podemos comprobar al cotejar las figuras 15 y 18 . En todo caso hay que señalar que, una vez culminado todo este proceso actualmente en marcha, con 17 planes aprobados, 2 en tramitación y 3 en redacción, y como apreciamos en el cuadro 1, casi el $80 \%$ de la población andaluza residirá en algún municipio adscrito a uno de estos ámbitos de planificación subregional, si bien esto afectará a poco más del $40 \%$ de los términos municipales andaluces y a menos del $37 \%$ de la superficie regional, de forma que, evidentemente, se ha optado por atender en primer lugar a las denominadas aglomeraciones urbanas y ámbitos litorales de Andalucía, como zonas más pobladas de la Comunidad.

ISSN: 0212-8594 ISSN-e: 2340-2776. № DOI: http://dx.doi.org/10.12795/rea.2013.i30.03 REA 30 (2013):48-77 
Redes para la cooperación a distintas escalas: Asociacionismo municipal, regiones europeas y programas transnacionales.

Cuadro 1. Afección de los planes previstos de Ordenación del Territorio de ámbito subregional en Andalucía.

\begin{tabular}{|l|l|l|l|}
\hline ÁMBITO ESPACIAL & HABITANTES EN 2010 & $\begin{array}{l}\text { NÚMERO DE } \\
\text { MUNICIPIOS }\end{array}$ & SUPERFICIE EN KM2 \\
\hline TOTAL ANDALUCÍA & 8.370 .975 & 771 & $87.597,4$ \\
\hline $\begin{array}{l}\text { TOTAL Planes } \\
\text { Subregionales de OT }\end{array}$ & 6.543 .710 & 315 & $31.650,8$ \\
\hline$\%$ / ANDALUCÍA & $78,170 \%$ & $40,85 \%$ & $36,13 \%$ \\
\hline
\end{tabular}

Fuente: Elaboración propia a partir datos de la Web de la Consejería de Agricultura, Pesca y Medio Ambiente de la Junta de Andalucía.

Figura 18. Situación espacial actual en la elaboración de los planes de Ordenación del Territorio de ámbito subregional en Andalucía.

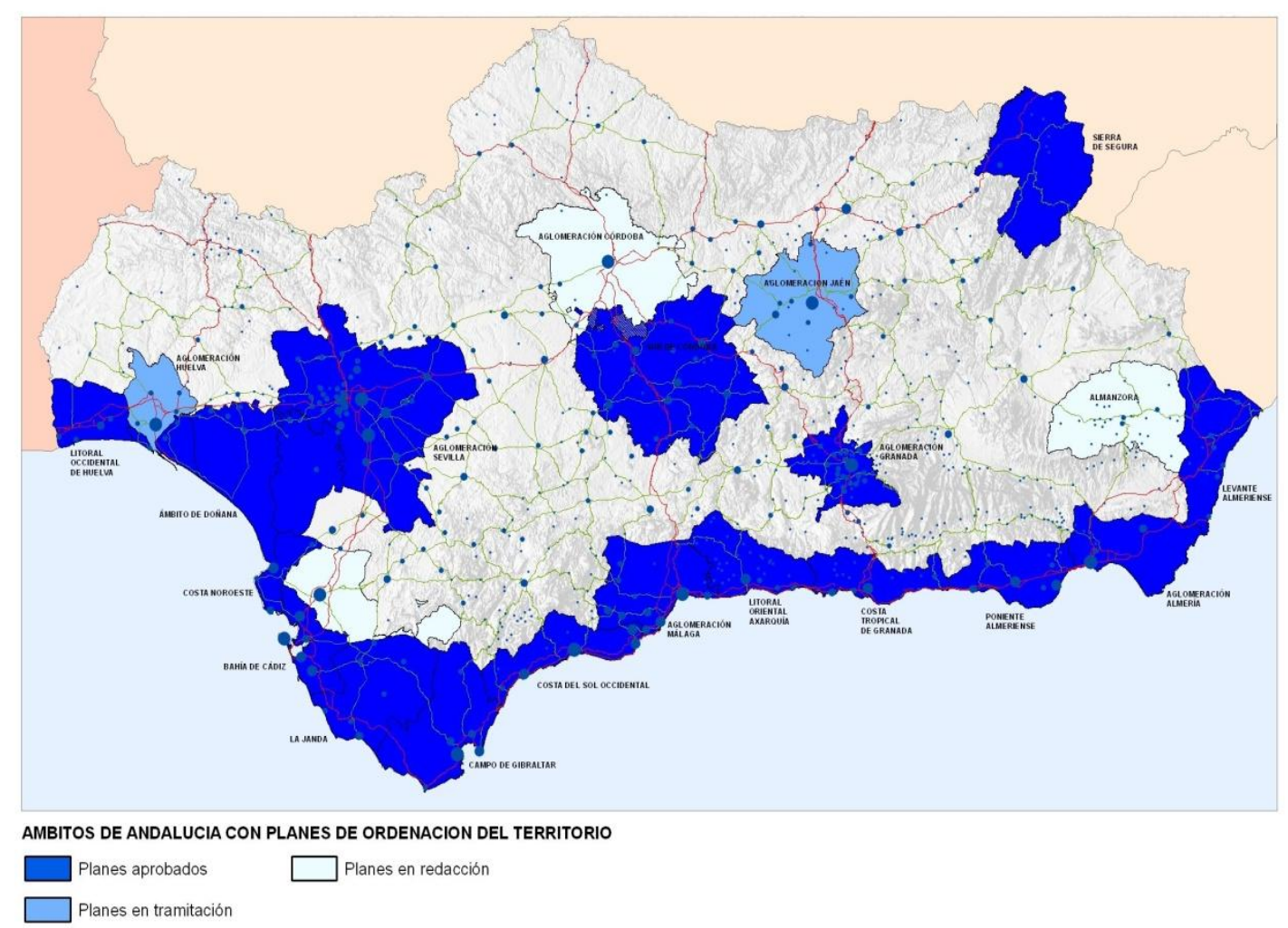

Fuente:

http://www.juntadeandalucia.es/medioambiente/site/portalweb/menuitem.7e1cf46ddf59bb227a9ebe 205510e1ca/?vgnextoid=5d4e6d15fad28310VgnVCM1000001325e50aRCRD\&vgnextchannel=91de8a3c 73828310VgnVCM2000000624e50aRCRD

ISSN: 0212-8594 ISSN-e: 2340-2776. № DOI: http://dx.doi.org/10.12795/rea.2013.i30.03 REA 30 (2013):48-77

http://www.publius.us.es/estudios_andaluces 


\section{BIBLIOGRAFÍA.}

Alianza de Civilizaciones (Naciones Unidas): http://www.unaoc.org/

Antón Burgos, Francisco Javier y Córdoba Y Ordoñez, Juan (2003): “Análisis neuronal y redes de transporte", en Servicios y transportes en el desarrollo territorial de España (coordinador, Enrique López Lara), Sevilla, páginas 337-346.

Benabent Fernández de Córdoba, Manuel (coordinador, 1998): Estudio territorial para la delimitación de ámbitos comarcales en Andalucía. Arenal Consultores (inédito).

Burgueño Rivero, J. (2001): "Geografía y administración: proyectar territorios en el siglo XXI», en Boletín de la Asociación de Geógrafos Españoles, no 32, págs. 191-207.

Cano García, G. (director y coordinador, 1990): Geografía de Andalucía, volumen VII, Política territorial y organización del espacio en Andalucía. Cádiz, Ed. Tartessos.

Cano García, G. (2002): «Una propuesta de comarcalización para Andalucía», en tomo $X$ de GEA XXI Conocer Andalucía. Ed. Tartessos, págs. 11-85.

Cano García, G. (2006): "Las ciudades andaluzas en el siglo XIX. Territorio y desarrollo", en Revista de Estudios Andaluces, no 26. Sevilla, Secretariado de Publicaciones de la Universidad, págs. 183-238.

Capel, Horacio (2003): “Una mirada histórica sobre los estudios de redes de ciudades y sistemas urbanos", GeoTrópico, online, 1, páginas 30-65. (C GeoLat, Bogotá, Colombia.

Capel, Horacio y Urteaga, Luis (1986): "La geografía en un curriculum de ciencias sociales", en Geo Crítica Cuadernos Críticos de Geografía Humana, número 61, Barcelona, 36 páginas.

Consejería de Educación y Ciencia (1991): Mapa Escolar de Andalucía 90-91, Sevilla, Junta de Andalucía, 567 páginas.

Consejería de Obras Públicas y Transportes (1999): Bases y Estrategias del Plan de Ordenación del Territorio de Andalucía. Sevilla, Junta de Andalucía.

Contreras, G.A. (2011): "Asociacionismo en red para la planificación del desarrollo turístico sostenible. El caso del río Guadalquivir y sus principales afluentes" en Revista de Estudios Andaluces, no 28. Sevilla, Secretariado de Publicaciones de la Universidad de Sevilla, págs. 34-54.№ DOI: http://dx.doi.org/10.12795/rea.2011.i28.03

Estudio DMC Geografía: http://estudiodmc.wordpress.com/

Fundación Tres Culturas del Mediterráneo: http://www.tresculturas.org/

Gavira, A. (2011): "Redes de transporte ferroviario metropolitano en Andalucía" en Revista de Estudios Andaluces, no 28. Sevilla, Secretariado de Publicaciones de la Universidad de Sevilla, págs.70-92. № DOI: http://dx.doi.org/10.12795/rea.2011.i28.05

Haggett, Peter (1965): Locational Analysis in Human Geography. London, Edward Arnold. Trad. al castellano de J. M. Obiols, Análisis locacional en Geografía humana. Barcelona, Gustavo Gili, 1976.

Haggett, Peter y Chorley, Richard J. (1969): Network analysis in geography. London, Edward Arnold.

ISSN: 0212-8594 ISSN-e: 2340-2776. № DOI: http://dx.doi.org/10.12795/rea.2013.i30.03 
Iglesias, Marcela (coordinadora) y otros (2011): La cooperación transfronteriza Andalucía-Norte de Marruecos. Balance y perspectivas. Sevilla, Consejería de la Presidencia de la Junta de Andalucía, 230 páginas.

Jurado, J.M. (1991): Delimitaciones comarcales en Andalucía. Revista de Estudios Andaluces. Vol 17, pp.1-38.

Ley Orgánica 6/1981, de 30 de diciembre, de Estatuto de Autonomía para Andalucía.

Ley 7/1993, de 27 de julio, Reguladora de la Demarcación Municipal de Andalucía.

Ley 23/1998, de 7 de julio, de Cooperación Internacional para el Desarrollo.

Ley Orgánica 2/2007, de 19 de marzo, de Reforma del Estatuto de Autonomía para Andalucía.

Ley 5/2010, de 11 de junio, de Autonomía Local de Andalucía.

Márquez Dominguez, Juan Antonio (1998): La apuesta por el desarrollo local. Huelva, Caja Rural.

Márquez Domínguez, Juan Antonio (coordinador, 2011): Cooperación Transfronteriza Andalucía-Algarve-Alentejo, XI Congreso de Ciencia Regional de Andalucía 2009. Huelva, Universidad y Asociación Andaluza de Ciencia Regional, 54 páginas más CDROM.

Márquez Domínguez, Juan Antonio (director, 2012): Desarrollo en la frontera del Bajo Guadiana. Documentos para la cooperación luso-andaluza. Huelva, Servicio de Publicaciones de la Universidad, 55 páginas más CD-ROM.

Plan de Ordenación del Territorio de Andalucía, Decreto 206/2006, de 28 de noviembre. Consejería de Obras Públicas y Transportes de la Junta de Andalucía.

Planes de Ordenación del Territorio de ámbito subregional de Andalucía: http://www.juntadeandalucia.es/medioambiente/site/portalweb/menuitem.220de82 26575045b25f09a105510e1ca/?vgnextoid=91de8a3c73828310VgnVCM2000000624e5 OaRCRD\&vgnextchannel=c5ba28b120b78310VgnVCM2000000624e50aRCRD

Política Europea de Vecindad de la Unión Europea: http://ec.europa.eu/world/enp/welcome_en.htm

Política Regional de la Unión Europea: http://ec.europa.eu/regional_policy/index_pl.cfm

Registro de Entidades Locales (Ministerio de Hacienda y Administraciones Públicas del Reino de España): http://ssweb.mpt.es/REL/

Ventura Fernández, J. y Fernández Latorre, M. (2011): «Escalas intermedias y el papel de los servicios en la Ordenación del Territorio andaluz», en Servicios, globalización y territorio, tomo 1 (Hernández Luis, J., editor), págs. 373-392. 
Ventura Fernández, J. y Moreno Navarro, J.G. (2011): “Nodos, redes y áreas de desarrollo en el entorno del Estrecho de Gibraltar", en Cooperación Transfronteriza Andalucía-Algarve-Alentejo (Márquez Domínguez, coordinador). Huelva, Universidad y Asociación Andaluza de Ciencia Regional, págs. 90 a 160 del CD-ROM.

Web profesional del Prof. Dr. Jesús Gabriel Moreno Navarro: http://personal.us.es/jgamore/

Zoido Naranjo, Florencio (1995-1996): “Ordenación del territorio: evolución reciente de las principales estructuras y sistemas territoriales", en Boletín de la Asociación de Geógrafos Españoles, №.s 21-22. Toledo, Asociación de Geógrafos Españoles (AGE), págs. 67-79.

Zoido Naranjo, Florencio (coordinador; 2001): Informe de Desarrollo Territorial de Andalucía. Universidad de Sevilla, 311 páginas.

Zoido Naranjo, F. y Caravaca Barroso, I. (coordinadores, 2005): Andalucía: segundo Informe de Desarrollo Territorial. Sevilla, Secretariado de Publicaciones de la Universidad de Sevilla. 